\title{
1 COLD-INDUCED HYPERPHAGIA REQUIRES AGRP NEURON ACTIVATION IN MICE
}

2 Jennifer D. Deem¹, Chelsea L. Faber ${ }^{1}$, Christian Pedersen², Bao Anh Phan ${ }^{1}$, Sarah A. Larsen ${ }^{1}$,

3 Kayoko Ogimoto ${ }^{1}$, Jarrell T. Nelson ${ }^{1}$, Vincent Damian ${ }^{1}$, Megan A. Tran ${ }^{1}$, Richard D. Palmiter ${ }^{3}$,

4 Karl J. Kaiyala ${ }^{4}$, Jarrad M. Scarlett ${ }^{1,5}$, Michael R. Bruchas ${ }^{6-8}$, Michael W. Schwartz ${ }^{1}$ and Gregory

5 J. Morton ${ }^{1}$

6

$7 \quad{ }^{1}$ UW Medicine Diabetes Institute, Department of Medicine, University of Washington, Seattle, WA, 8 USA.

$9 \quad{ }^{2}$ Department of Bioengineering, University of Washington, Seattle, WA, USA.

$10{ }^{3}$ Department of Biochemistry, Howard Hughes Medical Institute, University of Washington,

11 Seattle, WA, USA

$12{ }^{4}$ Department of Oral Health Sciences, School of Dentistry, University of Washington, Seattle, WA, 13 USA.

$14{ }^{5}$ Department of Pediatric Gastroenterology and Hepatology, Seattle Children's Hospital, Seattle, 15 WA, USA.

$16{ }^{6}$ Department of Anesthesiology and Pain Medicine, University of Washington, Seattle, WA, USA.

$17{ }^{7}$ Department of Pharmacology, University of Washington, Seattle, WA, USA.

$18{ }^{8}$ Center for the Neurobiology of Addiction, Pain, and Emotion, University of Washington, Seattle, 19 WA, USA.

\section{Address for correspondence:}

22 Michael W. Schwartz

23 UW Medicine Diabetes Institute,

24 Department of Medicine,

25 University of Washington

26750 Republican St, F771, Box 358062 
bioRxiv preprint doi: https://doi.org/10.1101/2020.05.21.107896; this version posted May 25, 2020. The copyright holder for this preprint (which

was not certified by peer review) is the author/funder, who has granted bioRxiv a license to display the preprint in perpetuity. It is made available under aCC-BY 4.0 International license.

27 Seattle, Washington, 98109, USA.

28 Phone:(206) 897-5292 Fax: (206) 897-5293

29 E-mail: mschwart@uw.edu 


\section{ABSTRACT}

31 To maintain energy homeostasis during cold exposure, the increased energy demands of

32 thermogenesis must be counterbalanced by increased energy intake. To investigate the

33 neurobiological mechanisms underlying this cold-induced hyperphagia, we asked whether agouti-

34 related peptide (AgRP) neurons are activated when animals are placed in a cold environment

35 and, if so, whether this response is required for the associated hyperphagia. We report that AgRP-

36 neuron activation occurs rapidly upon acute cold exposure, as do increases of both energy

37 expenditure and energy intake, suggesting the mere perception of cold is sufficient to engage each of these responses. We further report that silencing of AgRP neurons selectively blocks the

39 effect of cold exposure to increase food intake. Together, these findings establish a

40 physiologically important role for AgRP neurons in the hyperphagic response to cold exposure.

42 Keywords: Agouti-related peptide, body temperature, DREADD, energy intake, energy 43 expenditure, thermoregulation, fiber photometry, hyperphagia.

Abbreviations: AgRP, Agouti-related peptide; ARC, arcuate nucleus; NPY, neuropeptide Y; POMC, pro-opiomelanocortin; PMCH, pro-melanin concentrating hormone; MPA, medial preoptic

47 area; ventromedial preoptic area (VMPO); $\mathrm{DMH}$, dorsomedial hypothalamus; PVN, 48 paraventricular nucleus; PBN, parabrachial nucleus; rRPa, rostral raphe pallidus; AAV, adeno49 associated virus, GCaMP6s, genetically-encoded calcium indicator, version 6s; DREADD, 50 designer receptor activated by a designer drug; hM4Di, inhibitory DREADD receptor; CNO, 51 clozapine-N-oxide (CNO). 


\section{INTRODUCTION}

57 In homeothermic species, maintenance of euthermia in the face of a wide range of ambient

58 temperatures is critical for survival. In small homeotherms, countering cold stress requires not

59 only that adaptive adjustments of heat production occur rapidly and potently, but that they are

60 achieved without depleting body fuel stored in the form of fat (Gordon, 1993). Thus, when animals

61 are housed in a cool environment, energy expenditure increases rapidly and markedly to generate

62 the heat needed to maintain core body temperature (Cannon \& Nedergaard, 2010), and a

63 compensatory hyperphagic response prevents changes to body fat mass (Kaiyala, et al., 2015;

64 Ravussin, et al., 2014). While much is known regarding the neurocircuitry underlying cold-induced

65 thermogenesis (Madden, et al., 2019; Nakamura, et al., 2011; Tan, et al., 2018), the origins of cold-induced hyperphagia remain poorly understood.

68 One potential explanation for cold-induced hyperphagia is that it is mounted as a secondary

69 response to the negative energy-balance state that results from cold-induced thermogenesis,

70 analogous to what occurs in other states of negative energy balance. During caloric restriction,

71 for example, the imposed negative energy balance and the associated reduction of body fat stores

72 drives activation of adaptive homeostatic responses aimed at returning body fat stores to pre-

73 intervention values. Reduced energy expenditure and increased food-intake drive are major

74 components of this adaptive response, and both are thought to be primarily driven by humoral

75 signals indicative of a negative energy state (e.g., reductions of leptin and insulin) (Schwartz, et

76 al., 2000). It has, therefore, been reasonably assumed that the hyperphagic response to cold

77 requires the same negative energy-state signals, and this hypothesis is supported by studies that

78 have been conducted over time periods sufficient to induce hormonal changes (Bing, et al., 1998;

79 Hardie, et al., 1996; Puerta, et al., 2002). 
81 Among central targets of these humoral feedback signals are neurons that express agouti-related

82 peptide (AgRP) located in the hypothalamic arcuate nucleus (ARC) (Hahn, et al., 1998) which,

83 when activated, potently stimulate feeding (Aponte, et al., 2010; Atasoy, et al., 2012; Krashes, et

84 al., 2011). However, recent evidence suggests that AgRP neurons are not regulated solely by

85 humoral signals (Hahn, et al., 1998; Schwartz, et al., 2000; Zimmer, et al., 2019), but also by feed-

86 forward mechanisms (Chen, et al., 2016; Lowell, et al., 2019) involving neurocircuits that integrate

87 sensory cues from the environment (Betley, et al., 2015; Chen, et al., 2015, Mandelblat-Cerf, et

88 al., 2015) such that a negative energy state may be prevented. Based on these observations, we

89 hypothesized a role for AgRP neuron activation in the adaptive increase of food intake induced

90 by cold exposure.

91

92

93 


\section{RESULTS}

95 Effect of chronic cold exposure on determinants of energy balance and hypothalamic neuropeptide expression.

97 Our first goal was to confirm previous findings regarding the effect of chronic cold exposure on

98 energy homeostasis in normal mice. Using a mild, chronic cold-exposure paradigm $\left(14^{\circ} \mathrm{C}\right.$ for 5

99 days) and comparing outcomes to mice housed at room temperature $\left(22^{\circ} \mathrm{C}\right)$ (Figure $\left.1 \mathrm{~A}\right)$, we

100 found that, as expected (Cannon \& Nedergaard, 2004; Morrison, et al., 2014), core body

101 temperature did not change significantly relative to controls housed at room temperature (Figure

102 1B), presumably owing to an associated increase of heat production (Figure 1C). This

103 thermogenic response was accompanied by a proportionate increase of energy intake (Kaiyala,

104 et al., 2015; Ravussin, et al., 2014; Vallerand, et al., 1986) (Figure 1D), such that neither body 105 weight nor body fat mass changed significantly over the course of the study (Figure 1E-G). 106 Moreover, neither respiratory quotient $(R Q)$ nor ambulatory activity changed significantly (data 107 not shown).

109 At the end of the 5-day study, animals were sacrificed and hypothalami were rapidly dissected for 110 RNA isolation. To identify candidate hypothalamic mediators of this cold-induced hyperphagic 111 response, we used quantitative real-time PCR (qRT-PCR) to measure select neuropeptide 112 transcripts in isolated hypothalamic RNA. Despite our use of a mild cold-exposure paradigm, 113 consistent with previous work using stronger cold-exposure paradigms $\left(\sim 4-5^{\circ} \mathrm{C}\right)(\mathrm{McCarthy}$, et al., 114 1993; Tang, et al., 2009), we found increased expression of orexigenic Agrp and Npy mRNA in 115 animals housed at $14^{\circ} \mathrm{C}$ when compared to controls housed at room temperature (Figure 1H), 116 while expression of Pomc and Pmch remained unchanged (Figure 1I). This evidence of enhanced 117 Agrp mRNA expression cannot be attributed to reductions of either food intake or body fat stores, 118 since the former was actually increased and the latter unchanged throughout the study period. 
120 to cold-induced hyperphagia.

A

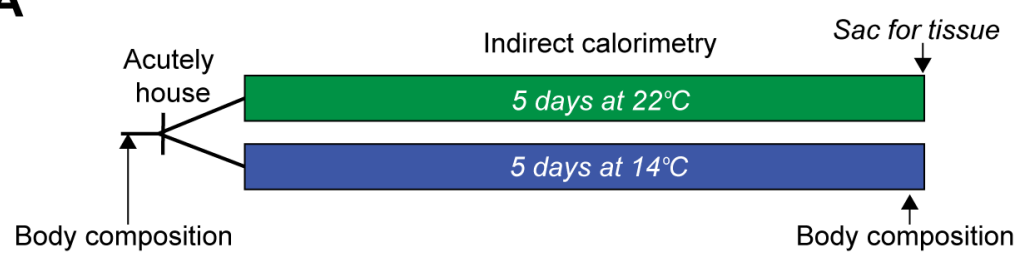

B

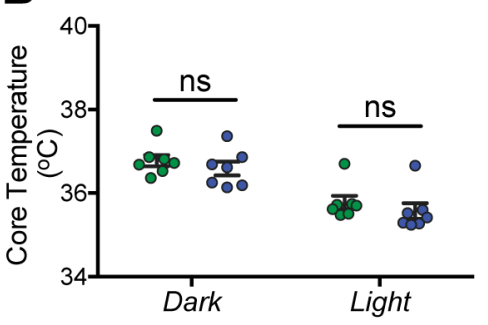

E
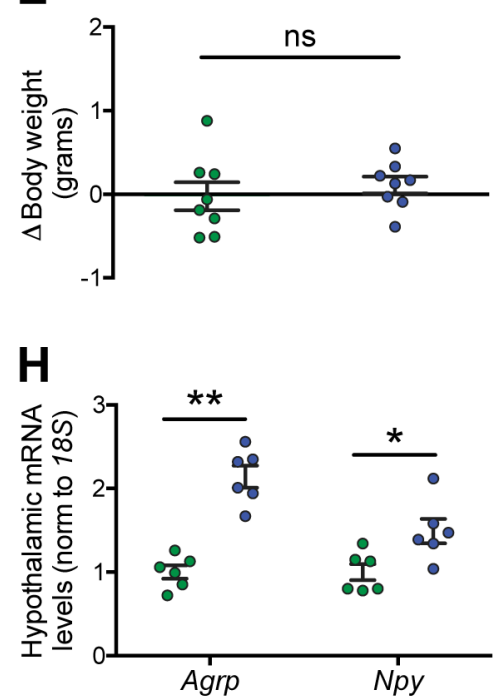

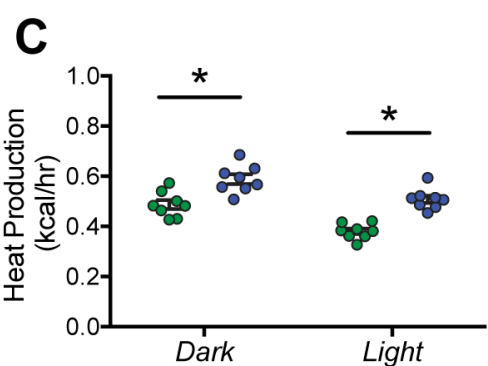

$\mathbf{F}$
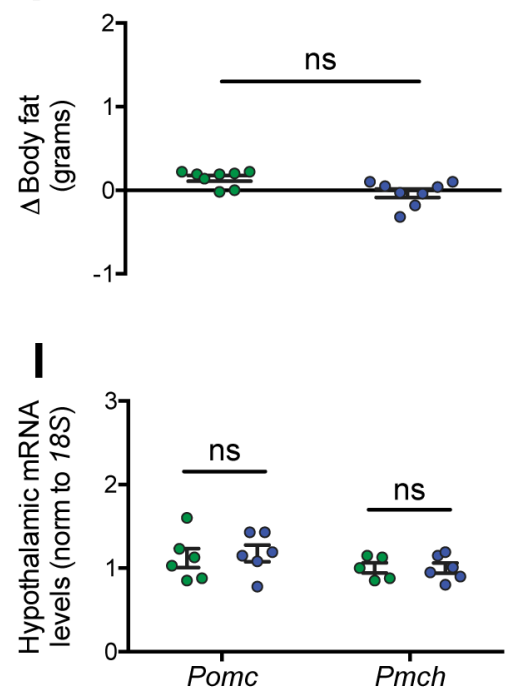

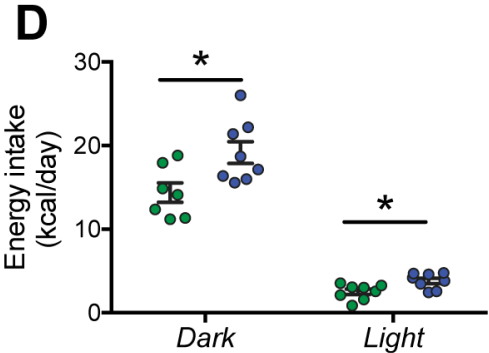

G

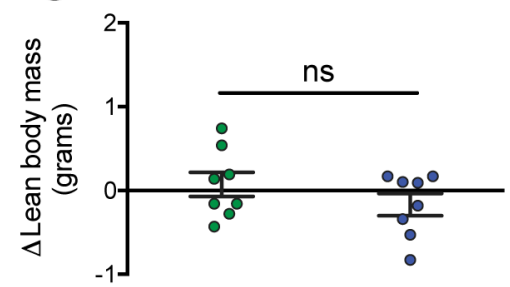

- $22^{\circ} \mathrm{C}$

- $14^{\circ} \mathrm{C}$
121

Figure 1. Effect of chronic cold exposure on determinants of energy balance and hypothalamic neuropeptide gene expression.

(A) Adult male, wild-type mice were housed at the start of the dark cycle following bodycomposition measures and were maintained in temperature-controlled chambers set to either mild cold $\left(14^{\circ} \mathrm{C}\right)$ or, as control, room temperature $\left(22^{\circ} \mathrm{C}\right)$ for 5 days. Following a final body-composition analysis, animals were sacrificed and hypothalamic punches rapidly dissected. (B) Mean dark and light cycle core body temperature, (C) heat production, (D) and energy intake over 5 days while housed at either $22^{\circ} \mathrm{C}$ or $14^{\circ} \mathrm{C}$. (E) Change in body weight, (F) body fat (G) and lean body mass at study end in the same mice, $n=7-8 /$ group, mean \pm SEM. Student's t-test, ${ }^{*} p<0.05$ vs. $22^{\circ} \mathrm{C}$. Hypothalamic mRNA levels of $(\mathbf{H})$ agouti-related peptide (Agrp) and neuropeptide Y (Npy), (I) pro-opiomelanocortin $(P o m c)$ and pro-melanin concentrating hormone (Pmch) were determined by $q R T-P C R, n=6 /$ group, mean \pm SEM. Student's t-test, ${ }^{*} p<0.05,{ }^{* *} p<0.01$ vs. $22^{\circ} \mathrm{C}$. 
The increases of energy expenditure and energy intake during cold exposure are rapid in

137 onset.

138 To delineate in greater detail the timing of the onset of feeding and metabolic responses to mild

139 cold exposure, we commenced serial metabolic measurements starting when mice were placed

140 into metabolic cages (to which they had been previously acclimated) that were inside

141 environmental chambers that were either pre-cooled $\left(14^{\circ} \mathrm{C}\right)$ or set at room temperature $\left(22^{\circ} \mathrm{C}\right)$ in

142 a randomized, cross-over manner (Figure 2A). Our findings show that the increase of heat

143 production associated with the change of ambient temperature increased rapidly, such that the

144 thermogenic response needed to maintain core temperature was detected within 5 min (Figure

145 2B) and remained elevated for the duration of the 24-h study (Figure 2C). Somewhat surprisingly,

146 we also found that upon acute cold exposure, the increase of food intake required to offset

147 heightened thermogenic demand was equally swift (Figure 2D). By comparison, neither

148 respiratory quotient nor ambulatory activity was affected during cold exposure, suggesting that

149 they are unlikely to play an important role in the adaptive response to this challenge

150 (Supplemental Figure 1). Like the increase of heat production, the initial increase in the rate of

151 food consumption was maintained throughout both light and dark cycles (Figure 2E). Based on

152 the rapidity of this feeding response, we infer that it was unlikely to have resulted from any

153 detectable depletion of body fat or associated circulating signal (e.g., leptin). We interpret these

154 findings as favoring a model in which the perception of cold is sufficient to increase both food

155 intake and energy expenditure rapidly and in parallel, independently of feedback signals that 156 might be subsequently recruited. 
A

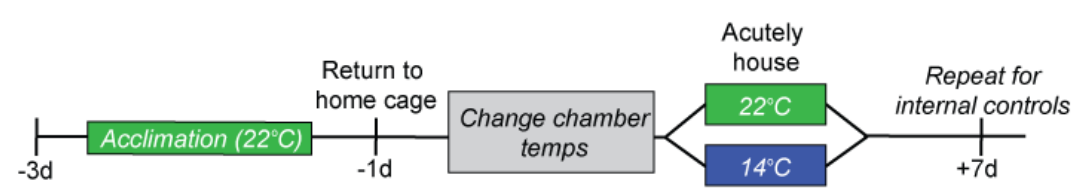

B

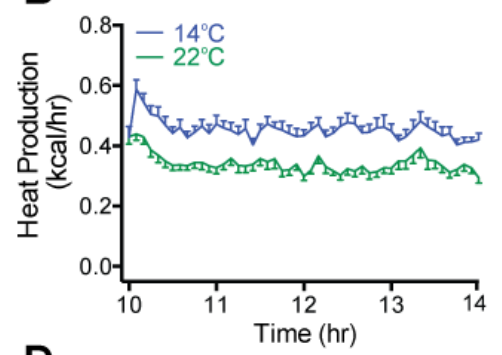

D

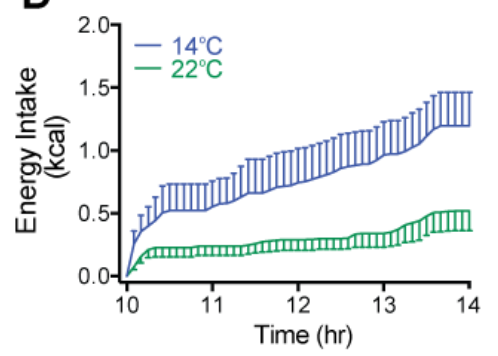

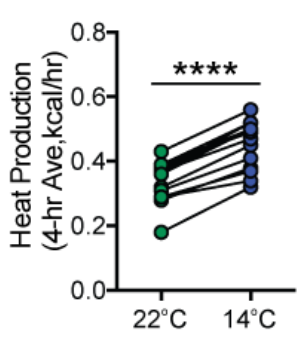

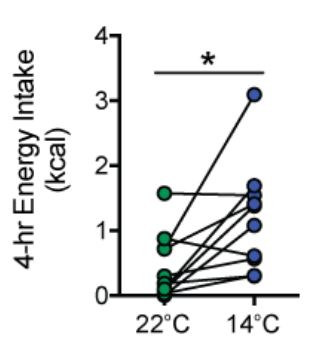

C
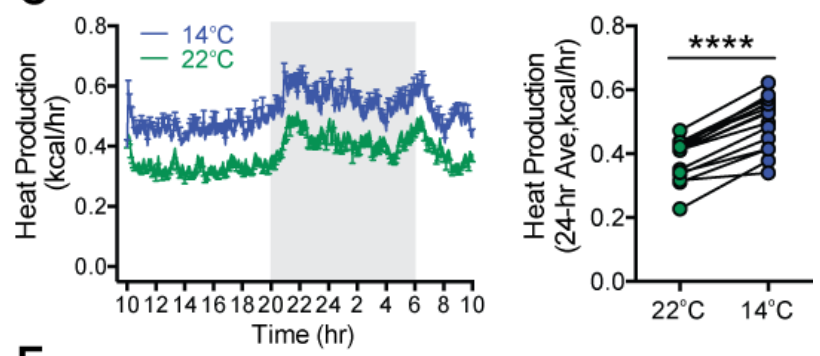

E

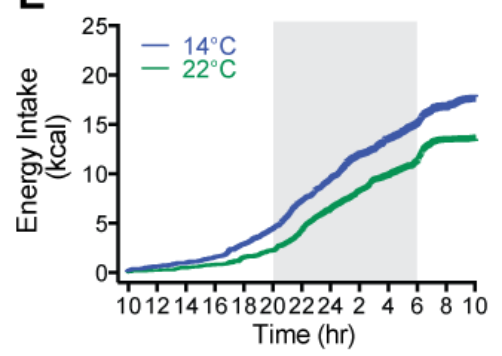

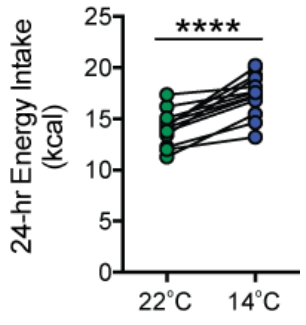

157

\section{Figure 2. Acute mild cold exposure rapidly increases both energy expenditure and energy intake.}

(A) Adult male wild-type mice were acutely housed in temperature-controlled chambers set to either mild cold $\left(14^{\circ} \mathrm{C}\right)$ or, as control, room temperature $\left(22^{\circ} \mathrm{C}\right)$. Time-series and mean heat production over (B) 4-hr and (C) 24-hr, respectively, and time-series and total energy intake over (D) 4-hr and (E) 24-hr, respectively beginning at 10:00 AM, n=10/group, mean \pm SEM. RMANOVA and paired Student's t-test, ${ }^{* * * *} p<0.0001,{ }^{*} p<0.05$.

\section{Mild cold exposure induces Fos in AgRP neurons.}

We next investigated whether the rapid onset of cold-induced hyperphagia is associated with AgRP neuron activation. To this end, we utilized transgenic AgRP-Cre:GFP mice to enable visualization of Fos protein, a marker of neuronal activation (Kovács, et al., 1998), in AgRP neurons after placement in cages previously set to mild cold $\left(14^{\circ} \mathrm{C}\right)$, room temperature $\left(22^{\circ} \mathrm{C}\right)$, or thermoneutrality $\left(\sim 30^{\circ} \mathrm{C}\right)$ for 90 minutes with food present. Relative to mice maintained at $22^{\circ} \mathrm{C}$, we found that both the total number of Fos+ cells in the ARC (Figure 3D) and, specifically, the number of Fos+ AgRP neurons (Figure 3E-F) was robustly increased within 90-min of coldexposure onset. As expected, we also found the expected cold-induced increases in Fos in other 
177 thermoregulatory control centers including the parabrachial nucleus (PBN), preoptic area (POA)

178 (Bratincsák \& Palkovits, 2004; Geerling, et al., 2016), dorsomedial hypothalamus (DMH) (Hunt,

179 et al., 2009), and rostral raphe pallidus (rRPa) (Supplemental Figure 2). Moreover, in contrast

180 to both $14^{\circ} \mathrm{C}$ and $22^{\circ} \mathrm{C}$, both the total number of Fos+ cells in the ARC and the number of Fos+

181 AgRP neurons was minimal in mice housed at $30^{\circ} \mathrm{C}$ (Figure 3D-F). This Fos response was

182 distributed equivalently across the entire rostral to caudal AgRP neuron population

183 (Supplemental Figure 3). Our finding that Fos+ AgRP neuron number increases at temperatures

184 below thermoneutrality (Figure 3F) identifies ambient temperature as a potential physiological

185 regulator of AgRP-neuron activity.

A

$A P:-1.17$ to -2.17
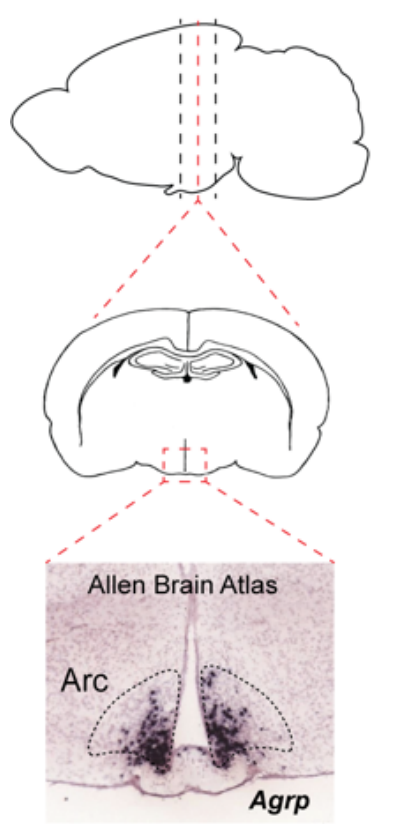

C

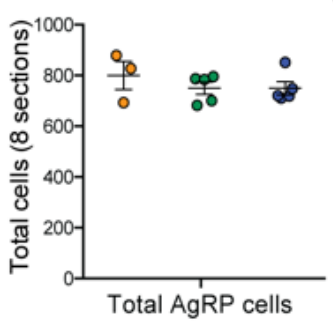

B

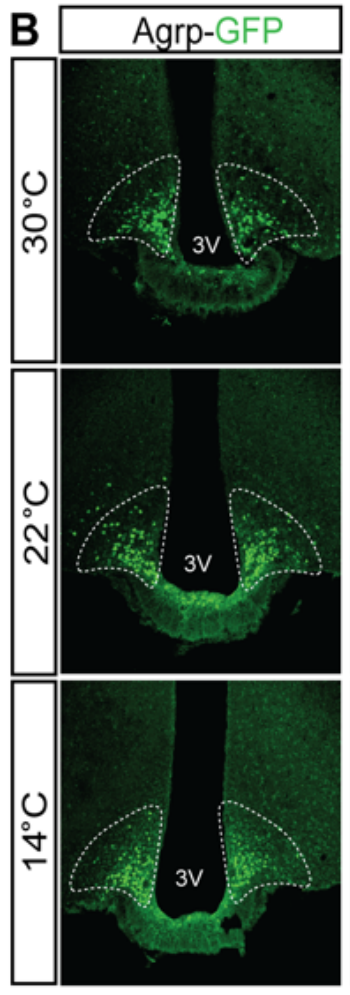

D

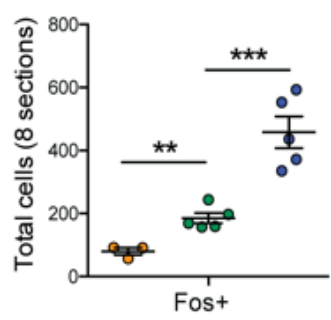

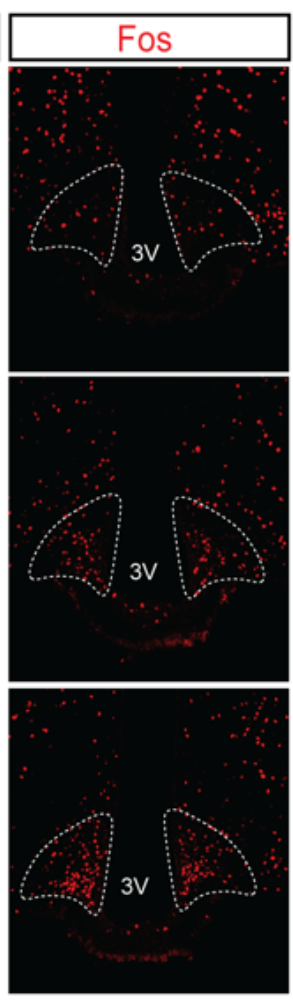

E

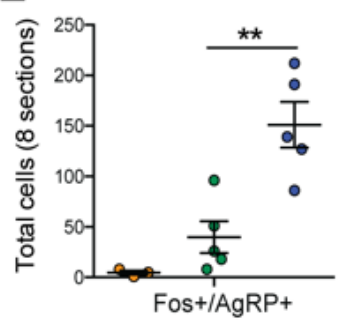

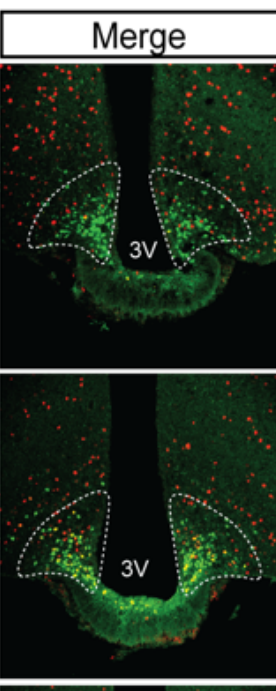
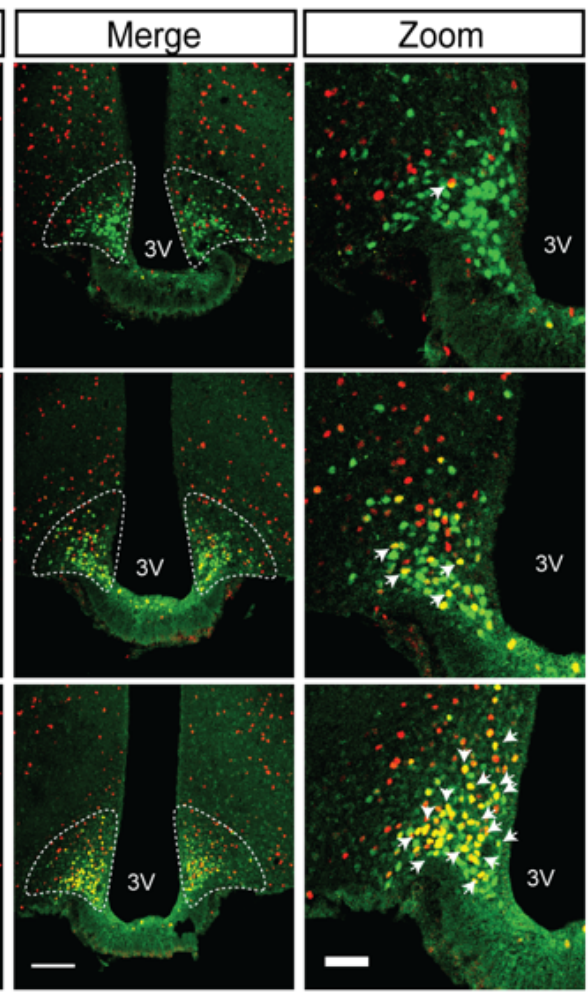

F

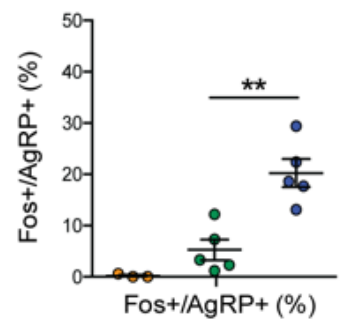


Figure 3. Acute mild cold exposure activates AgRP neurons.

188 (A) Representative sagittal and coronal images and Agrp hybridization in situ from Allen Brain 189 Institute of the ARC. (B) Immunohistochemical detection of AgRP-locus driven GFP (green), 190 Fos (red), and colocalization of GFP and Fos (two right panels) in the ARC of AgRP-Cre:GFP 191 mice 90 min after housing at either $14^{\circ} \mathrm{C}$ or $30^{\circ} \mathrm{C}$ or $22^{\circ} \mathrm{C}$. Quantitation of (C) total $\mathrm{AgRP}^{+}$cells, 192 (D) total Fos ${ }^{+}$cells and the total number (E) and percent (F) of AgRP neurons that co-express 193 Fos across 8 rostral to caudal sections of the ARC (AP: -1.17 to -2.17 ). Thin bar $=100 \mu \mathrm{m}$, Thick 194 bar $=50 \mu \mathrm{m}, \mathrm{n}=3-5 /$ group, mean \pm SEM. One-way ANOVA, ${ }^{* *} \mathrm{p}<0.001,{ }^{* *} \mathrm{p}<0.01,{ }^{*} \mathrm{p}<0.05$ vs. 22 $195{ }^{\circ} \mathrm{C}$.

\section{Mild cold exposure rapidly increases Agrp neuron activity}

198 To definitively establish the timing with which AgRP-neuron activity changes in relationship to cold 199 exposure, we applied fiber photometry of AgRP neurons in vivo during a thermal challenge. To

200 this end, AgRP-IRES-Cre mice received a unilateral injection of an adeno-associated virus (AAV) 201 containing a Cre-dependent, genetically-encoded calcium sensor GCaMP6s directed to the ARC 202 (Chen, et al., 2013), followed by implantation of an optical fiber at the injection site (Figure 4A203 B). After allowing 3 weeks for transgene expression and acclimation, validation of signal quality 204 was performed by examining the AgRP neuron response to food presentation in the fasted state. 205 Consistent with previous observations (Betley, et al., 2015; Chen, et al., 2019; Mandelblat-Cerf, 206 et al., 2015), we found that food presentation strongly and rapidly inhibited AgRP neuron activity, 207 as indicated by a strong reduction in GCaMP signal (Supplemental Figure 4). To determine 208 whether exposure to cold affects AgRP neuron activity, mice were placed in a custom-built 209 plexiglass cage modified to enable rapid control over the temperature sensed by the tethered 210 animal (Figure 4C). We predicted that if AgRP neurons contribute to cold-induced hyperphagia, 211 exposure to cold would activate AgRP neurons over a time frame that would either precede or 212 coincide with hyperphagia onset (Figure 2D). Consistent with this prediction, we found that when

213 the temperature of the platform was rapidly reduced from $30^{\circ} \mathrm{C}$ to $14^{\circ} \mathrm{C}$ (within $1 \mathrm{~min}$ ) an increase

214 in GCaMP activity was detected within seconds, consistent with an increase in AgRP neuronal 215 activity. Moreover, this effect was reversed by raising the temperature from $14^{\circ} \mathrm{C}$ back to $30^{\circ} \mathrm{C}$ 216 (Figure 4D-F). 
218 At the end of each study, animals were presented with a food pellet to establish intact inhibition

219 of AgRP neuron GCaMP activity. Although the animals were fed ad libitum prior to the study, a

220 clear inhibition of AgRP neuron GCaMP activity was present comparable to the changes seen

221 during temperature transitions, thus validating the photometry signal (Supplemental Figure 5).

222 Taken together, these findings indicate that AgRP neurons are rapidly activated in response to

223 cold exposure.

A

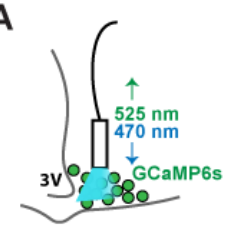

AgRP-IRES-Cre

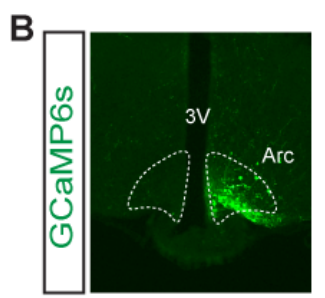

C

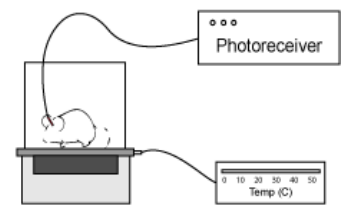

D $30^{\circ} \mathrm{C} \longrightarrow 14^{\circ} \mathrm{C}$
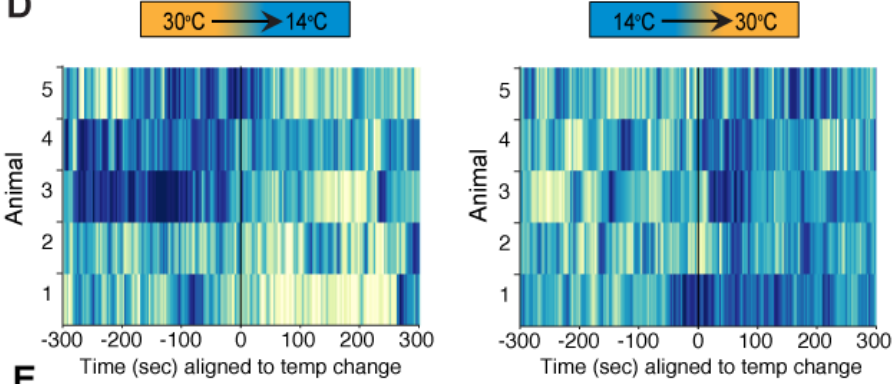

Z score

$\pi^{2}$

E
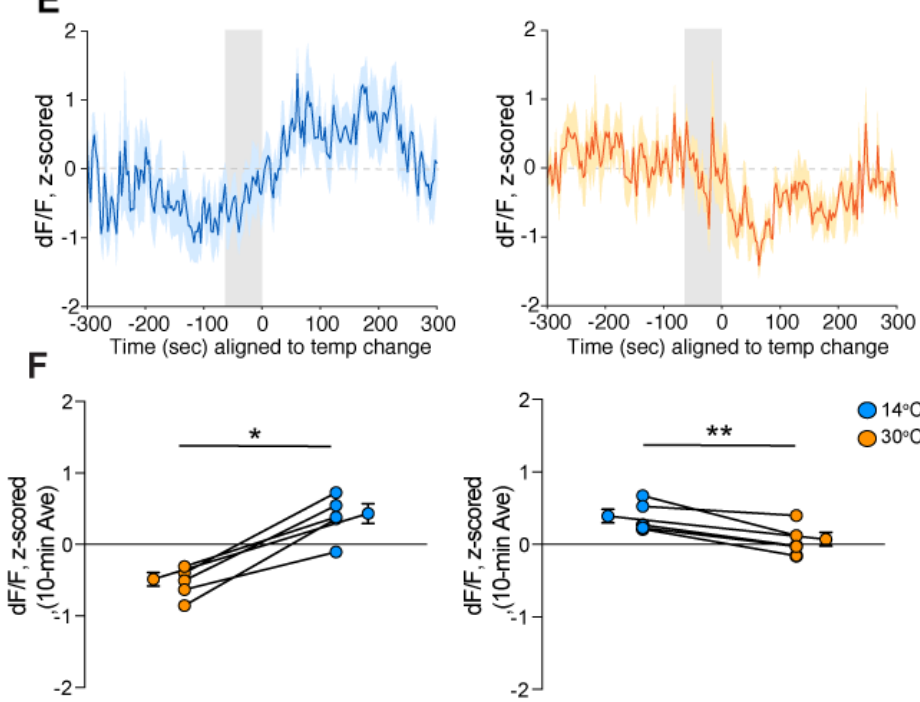
(A) Representative diagram of fiber photometry with fiber placement at ARC. (B) Unilateral GCaMP6s expression in AgRP neurons. (C) Representative diagram of experimental set up. (D) Heat maps of z-scored dF/F, (E) trace of averaged z-scored dF/F GCaMP6s signal, and (F) quantification of mean differences between $30^{\circ} \mathrm{C}$ and $14^{\circ} \mathrm{C}$ GCaMP activity during 10-minute exposure. Gray bar signifies 60-sec temperature-ramp transition, $n=5 / g r o u p$, mean \pm SEM. Student's paired t-test, ${ }^{* *} p<0.01,{ }^{*} p<0.05$.

\section{AgRP-neuron activity is necessary for cold-induced hyperphagia}

236 Having established that AgRP neurons are rapidly activated in response to mild cold exposure,

237 we next sought to determine whether this response is required for the associated hyperphagia.

238 To test this hypothesis, we utilized a chemogenetic approach in which AgRP-IRES-Cre mice

239 received bilateral microinjections into the ARC of an AAV construct containing a Cre-dependent

240 cassette encoding the inhibitory designer receptor activated by a designer drug (DREADD),

241 hM4Di:eYFP (Figure 5A). The transduced neurons can be detected by their eYFP expression

242 and, as expected, it was limited to the ARC (Figure 5B). Acclimated animals received an

243 intraperitoneal injection of clozapine-N-oxide (CNO) or its vehicle (saline) in a randomized

244 crossover manner, one hour prior to being placed into metabolic cages housed within

245 temperature-controlled chambers previously set at either $22^{\circ} \mathrm{C}, 30^{\circ} \mathrm{C}$ or $14^{\circ} \mathrm{C}$ for measures of

246 food intake and energy expenditure by indirect calorimetry for 4 hours (Figure 5C).

248 Based on our Fos and fiber-photometry data (Figures 3 and 4), we predicted that the effect of

249 chemogenetic AgRP-neuron inhibition would be robust in mice housed at $14^{\circ} \mathrm{C}$, but minimal at

$25030^{\circ} \mathrm{C}$, because AgRP neurons exhibit low activity at thermoneutrality. Consistent with this

251 prediction, we found that whereas inhibition of AgRP neurons had little effect on food intake in

252 mice housed at $30^{\circ} \mathrm{C}$ (Figure 5D), intake was strongly reduced in animals housed at $14^{\circ} \mathrm{C}$, while

253 intake was more modestly inhibited by $\mathrm{CNO}$ in mice housed at $22^{\circ} \mathrm{C}$ (Figure $\mathbf{5 F}$ and $\mathrm{H}$ ). The latter

254 finding is consistent with room temperature posing a thermal stress to mice (Abreu-Vieira, et al., 255 2015). 
257 The effect of AgRP-neuron inhibition appears to be selective for energy intake, as the cold-

258 induced increase of heat production was not affected (Figure 5E, G, I). In addition, there was no

259 significant effect of AgRP-neuron inhibition on either respiratory quotient or ambulatory activity at

260 any of the three ambient temperatures studied (Supplemental Figure 6). Taken together, these

261 findings suggest that AgRP-neuron activation is required for cold-induced hyperphagia,

262 neurocircuits underlying feeding and thermogenic responses to cold are distinct and separable

263 from one another, and some degree of cold stress (including housing at room temperature) is

264 required for food intake to be reduced by chemogenetic, AgRP-neuron inhibition under ad libitum

265 feeding conditions during the light cycle.

A

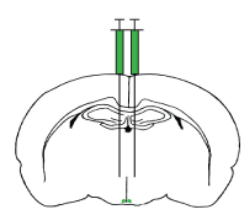

AgRP-IRES-Cre

C

D

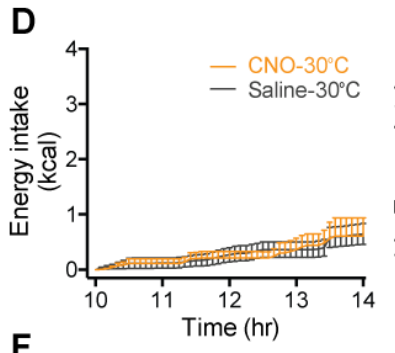

F
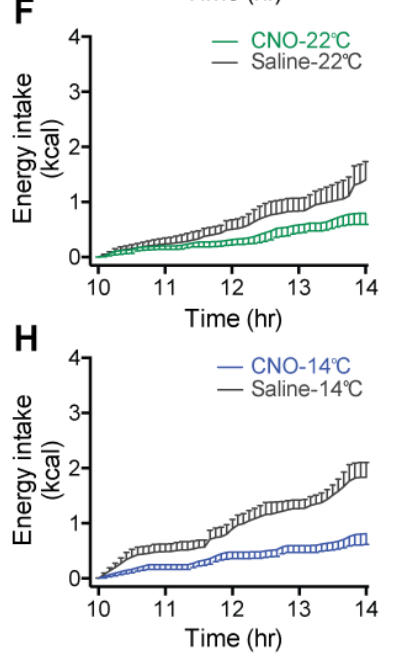

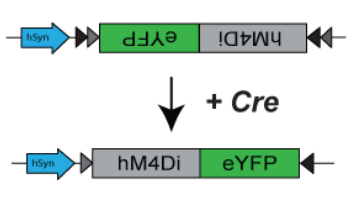

B

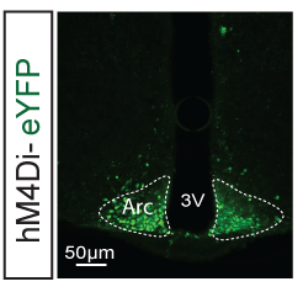

Repeat for internal controls

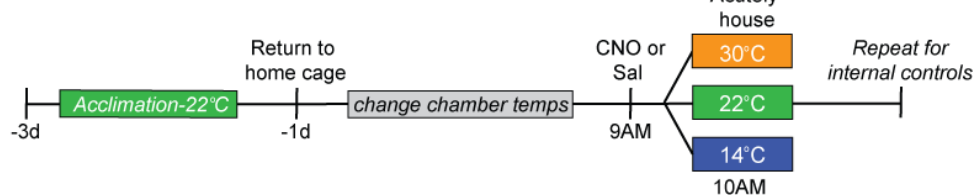

$10 \mathrm{AM}$
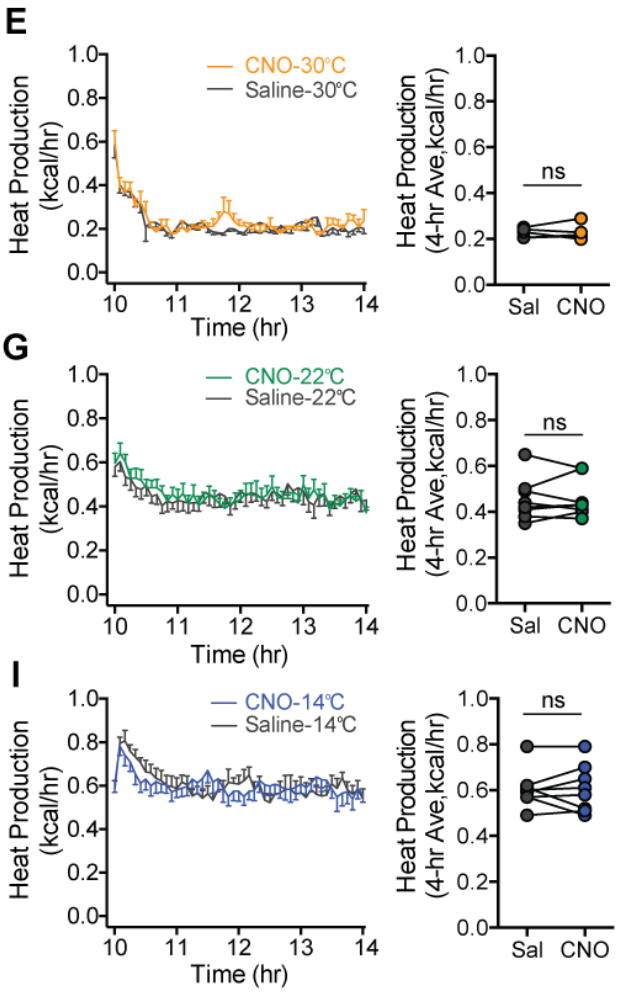
Figure 5. Cold-induced hyperphagia, but not thermogenesis, requires activation of AgRP neurons.

(A) Schematic depicting strategy for bilateral microinjection of the Cre-dependent inhibitory DREADD (hM4Di) virus into the ARC of AgRP-IRES-Cre mice. (B) Detection of bilateral hM4DieYFP in transduced AgRP neurons in the ARC. (C) Adult male hM4Di-eYFP AgRP-IRES-Cre mice were acclimated to temperature-controlled chambers set to $22^{\circ} \mathrm{C}$. Animals were returned to their home cages and chamber temperatures were adjusted overnight. In the morning, animals were dosed i.p. with either $\mathrm{CNO}$ or saline one hour prior to being acutely housed at either mild cold $\left(14^{\circ} \mathrm{C}\right)$, room temperature $\left(22^{\circ} \mathrm{C}\right)$, or thermoneutrality $\left(30^{\circ} \mathrm{C}\right)$ in a randomized, crossover manner. (D, F, H) 4-hr time-series and mean values for energy intake, and (E, G, I) 4-hr timeseries and mean values of heat production in hM4Di-eYFP AgRP-IRES-Cre mice that were housed at either $30^{\circ} \mathrm{C}, 22^{\circ} \mathrm{C}$ or $14^{\circ} \mathrm{C}$ after receiving an i.p. injection of either saline or CNO $n=6$ 8 group, Mean \pm SEM. RM-ANOVA and Student's t-test, ${ }^{* * *} p<0.001,{ }^{*} p<0.05$ vs. saline.

\section{DISCUSSION}

284 The tight coupling that exists between thermoregulation and energy homeostasis (Gordon, 1993;

285 Kaiyala, et al., 2015) enables animals to precisely maintain both core body temperature and body

286 fat mass across a wide range of ambient temperatures, so long as food is available (Kaiyala, et

287 al., 2015; Smith, et al., 1984; Thurlby, et al., 1979). Fundamental to this process is the precise

288 coupling between changes in energy expenditure and energy intake in response to changing

289 requirements for heat production (Armitage, et al., 1984; Kaiyala, et al., 2015; Thurlby, et al.,

290 1979). While cold-induced hyperphagia has been documented across many species, including

291 humans (Johnson \& Kark, 1947), the mechanisms underlying this response have received little

292 attention, especially when compared to the considerable literature describing how changes of

293 thermogenesis are coupled to changes of ambient temperature (Madden \& Morrison, 2019;

294 Rezai-Zadeh, et al., 2013). This relative lack of research interest may reflect the pervasive view

295 that rather than being an integral component of the thermoregulatory control system, cold-induced

296 hyperphagia is mounted as a compensatory response to the negative-energy balance state

297 induced by cold-induced thermogenesis. Our current data suggest that this perspective should be

298 revised. 
300 Given the well-documented role of AgRP neurons in physiological control of food intake and 301 energy homeostasis (Schwartz, et al., 2000; Timper, et al., 2017; Varela, et al., 2012), we

302 hypothesized that cold-induced hyperphagia is driven at least in part by activation of these

303 neurons. We report that in normal mice, AgRP neurons are rapidly activated by cold exposure

304 and that intact cold-induced hyperphagia requires this response, since it was blocked by acute

305 chemogenetic AgRP neuron silencing. We also show that the magnitude of food-intake reduction

306 induced by chemogenetic silencing of these neurons varies inversely with increasing ambient

307 temperature, such that the effect is more pronounced in colder environments relative to

308 thermoneutral conditions in which AgRP-neuronal activity is lower. Taken together, we conclude

309 that under our experimental conditions (e.g., in the absence of negative energy balance induced,

310 for example, by caloric restriction), the adaptive increase of food intake during acute cold

311 exposure depends upon increases in AgRP-neuron activity.

313 AgRP neurons are among the most studied hypothalamic neuronal populations involved in energy

314 homeostasis. These GABAergic neurons co-express the potent orexigenic neuropeptide Y (NPY)

315 and are found exclusively in the ARC (Hahn, et al., 1998). An adjacent neuronal population

316 expresses pro-opiomelanocortin (POMC), and whereas AgRP-neuron activation stimulates

317 feeding, POMC-neuron activation has the opposite effect (Schwartz, et al., 2000; Xu, et al., 2011).

318 Furthermore, AgRP and POMC neurons are reciprocally regulated by leptin (Schwartz, et al.,

319 2000; Sohn, et al., 2013) and other humoral signals, such that the effect of energy restriction to

320 reduce body fat stores (and plasma leptin levels) causes both activation of AgRP neurons and

321 inhibition of POMC neurons, a combined response that drives feeding until body fat stores and

322 plasma leptin levels return to baseline values (Schwartz, et al., 2017). These considerations raise

323 the possibility that the feeding response to cold is mounted as a compensatory response triggered

324 by increased thermogenesis, which in turn causes depletion of body fuel stores and associated 
325 reduction of adiposity negative feedback (e.g., falling plasma leptin levels) (Bing, et al., 1998;

326 Puerta, et al., 2002; Ricci, et al., 2000; Tang, et al., 2009). However, the rapidity with which AgRP

327 neurons are activated in response to cold exposure seems inconsistent with this type of negative-

328 feedback control. Nevertheless, humoral negative-feedback signals could certainly be recruited

329 over time and play a role in sustained feeding responses to a cold challenge, even if they are not

330 relevant to the initial hyperphagic response. Thus, investigation of the role of POMC neurons or

331 other neuronal cell types involved in homeostatic control of feeding is warranted.

333 Recent work has established that in addition to negative-feedback regulation by humoral signals

334 relevant to body fuel stores, AgRP-neuron activity is also influenced by "feed-forward" signals that

335 promote homeostasis by anticipating future need (Chen, et al., 2016; Lowell, 2019). Among

336 relevant feed-forward signals are cues from the environment that anticipate eating (e.g., the sight

337 or smell of food), which are presumably communicated indirectly to AgRP neurons via cortical

338 areas that process the relevant sensory input (Livneh, et al., 2017). How this information is

339 ultimately transmitted to AgRP neurons is unknown, but synaptic relays in the hypothalamic 340 paraventricular nucleus (PVN) (Krashes, et al., 2014), dorsomedial nucleus (DMH) (Garfield, et

341 al., 2016), and POA may play a role. The key point is that although food intake driven by AgRP-

342 neuron activation is commonly associated with states of negative energy balance and/or falling

343 leptin levels, these neurons can also be activated by sensory-related stimuli (Chen, et al., 2016;

344 Garfield, et al., 2016; Krashes, et al., 2014).

346 These considerations have relevance to our finding that AgRP neurons are rapidly activated

347 following exposure to a cold environment, and that the activity of these neurons at

348 thermoneutrality is lower. These observations are consistent with previous findings in neonates

349 suggesting that AgRP neurons are regulated by ambient temperature. Specifically, exposure of

350 P10 mice to a warm environment rapidly suppresses AgRP-neuron activity, whereas pup isolation 
351 (with reduced thermal insulation from dam and littermates) increases AgRP-neuron activity

352 (Zimmer, et al., 2019). Moreover, the time course of increased AgRP-neuron activity coincides

353 with the increase of both energy expenditure and energy intake elicited by cold exposure. By

354 commencing continuous monitoring upon placing mice in a pre-cooled cage (rather than waiting

355 for the cage to gradually cool to the desired temperature), we were able to show that energy

356 expenditure increases rapidly in response to cold exposure - such that the thermogenic response

357 needed to maintain core body temperature for the duration the study was achieved within 5 min.

358 Even more impressive is that cold-induced hyperphagia has a similarly rapid onset, at least in

359 mice studied during the mid-light cycle, when they are normally inactive and consume only a small

360 percentage of their daily calories (Ellacott, et al., 2010). We interpret the rapidity and synchrony

361 with which exposure to a cold environment activates AgRP neurons and engages feeding

362 responses as being consistent with control via a "feed-forward" mechanism, rather than control

363 by negative-feedback control, and future studies are warranted to test this hypothesis.

365 Our finding that blockade of cold-induced hyperphagia by chemogenetic inhibition of AgRP 366 neurons occurred despite having no effect on energy expenditure suggests that cold-induced 367 AgRP-neuron activation is required for the feeding, but not thermogenic response to this 368 challenge. We also report that AgRP-neuron inhibition is without effect on either respiratory 369 quotient or ambulatory activity in cold-exposed mice. Based on these findings, we conclude that 370 the primary contribution made by AgRP-neuron activation to the adaptive response to cold 371 exposure is to drive hyperphagic feeding.

372

373 In conclusion, we report that AgRP-neuron activation occurs rapidly during cold-exposure, and

374 that this response plays a key role to drive the associated hyperphagic, but not the thermogenic,

375 response to this stimulus. Further, we demonstrate that the contribution made by AgRP-neuron 376 activation to food consumption is dependent on ambient temperature, constituting a large fraction 
377 of intake during cold exposure while playing a lesser role in a thermoneutral environment. In

378 addition to advancing our understanding of the thermoregulatory system, insights into the

379 neurocircuitry linking thermoregulation to AgRP-neuron activity may help to identify novel

380 strategies for obesity treatment by blunting the associated hyperphagic response.

\section{MATERIALS AND METHODS}

\section{Animals}

383 All procedures were performed in accordance with NIH Guide for the Care and Use of Laboratory

384 Animals and were approved by the Institutional Animal Care and Use Committee at the University

385 of Washington. Mice were individually housed in a temperature-controlled room with either a

$386 \quad 12: 12 \mathrm{hr}$ or $14: 10 \mathrm{hr}$ light:dark cycle under specific-pathogen free conditions and were provided

387 with ad libitum access to water and fed a standard laboratory chow $(5001 ; 13 \%$ kcal fat, LabDiet,

388 St. Louis, MO), unless otherwise stated. Adult male C57BI/6 wild-type mice were obtained from

389 Jackson Laboratories, ME, while AgRP-IRES-Cre mice were kindly provided to us by Dr.

390 Streamson Chua, Jr (Albert Einstein College of Medicine) and have been previously described

391 (53). The AgRP-Cre:GFP knock-in mice (version 2, v2) used in this study were generated by Dr.

392 Richard Palmiter (University of Washington) by replacing the Cre:GFP cassette of the original line

393 (Sanz et al., 2015) with a new cassette designed to have attenuated expression of Cre:GFP. The

394 new cassette differs from the original by: (a) removing the nuclear localization signal from Cre,

395 (b) using a non-optimal initiation codon, (c) removing part of the N-terminal sequence of Cre, and

396 (d) adding a 3' untranslated region from the Myc gene that promotes a short mRNA half-life.

397 Crossing mice with this new (v2) line with a conditional reporter line of mice (Gt(ROSA)26-LSL-

398 TdTomato, Allen Institute Seattle WA) gives faithful expression only in AgRP neurons, unlike the

399 original line (Sanz, et al., 2015) which occasionally resulted in ectopic expression in many parts

400 of the brain. The new targeting construct was electroporated into G4 ES cells (C57BI/6 x 129/SV)

401 and clones with correct targeting were identified by Southern blot of DNA digested with BamH1;

4026 of 48 clones analyzed were correctly targeted. Three of these clones were injected into 
403 blastocysts from C57BI/6 mice and one of them gave chimeras with a high percentage of agouti

404 color. Those chimeras were bred with Gt(ROSA)26-FLPer mice to remove the frt-flanked Neo

405 gene. Thereafter, the mice were backcrossed to C57BI/6 mice for more than 6 generations before

406 our experiments were performed.

\section{Viral constructs}

409 Chemogenetic inhibition of AgRP neurons was achieved by microinjection of an AAV containing

410 Cre-dependent cassette for the inhibitory DREADD, AAV1-CAG-DIO-hM4Di-YFP-WPRE-bGHpA

411 (hM4Di: kindly provided by the laboratory of Dr. Larry Zweifel, University of Washington), into

412 brain areas containing Cre-expressing neurons (e.g., the ARC of AgRP-IRES-Cre mice).

413 Activation of the DREADD receptor was induced by intraperitoneal administration of the agonist,

414 clozapine-N-oxide (CNO, $1 \mathrm{mg} / \mathrm{kg}$, ip). For fiber-photometry experiments, we utilized an AAV

415 containing a Cre-dependent cassette for the genetically-encoded calcium indicator, GCaMP6s,

416 AAVDJ-EF1a-DIO-GCaMP6s-WPRE (UNC Viral Core, Chapel Hill, NC).

419 Stereotaxic viral injections were performed as described (Faber et al., 2018; Meek et al., 2016).

420 Briefly, animals were anesthetized using 1-3\% isoflurane, their head shaved and placed in three-

421 dimensional stereotaxic frame (Kopf 1900, Cartesian Research Inc., CA). For inhibitory DREADD

422 experiments, the skull was exposed with a small incision, and two small holes were drilled for 423 bilateral microinjection ( $400 \mathrm{nl} / \mathrm{side}$ ) of the inhibitory DREADD (hM4Di) AAV into the ARC of

424 AgRP-IRES-Cre mice at stereotaxic coordinates based on the Mouse Brain Atlas: A/P: -1.2, M/L:

$425+/-0.3$, D/V: -5.85 (Franklin \& Paxinos, 2013). For fiber photometry experiments, AAV was injected

426 using a unilateral and angled approach (A/P: $-1.8, \mathrm{D} / \mathrm{V}:-5.85,12^{\circ}$ angle from midline). After viral

427 injections, a fiberoptic ferrule (0.48 NA, $\varnothing 400 \mu \mathrm{m}$ core; Doric Lenses, Quebec, Canada) was

428 implanted using the same coordinates. All microinjections were performed using a Hamilton 
429 syringe with a 33-gauge needle at a flow rate of $100 \mathrm{~nL} / \mathrm{min}$ (Micro4 controller, World Precision

430 Instruments, Sarasota, FL), followed by a 5-min pause and slow withdrawal. Animals received a

431 peri-operative dose of buprenorphine hydrochloride $(0.05 \mathrm{mg} / \mathrm{kg} \mathrm{sc}$; Reckitt Benckiser, Richmond,

432 VA). After surgery, mice were allowed 3 weeks to recover to maximize virally-transduced gene

433 expression and to acclimate animals to handling and experimental paradigms prior to study.

434 Expression and fiber placement were verified post hoc in all animals, and any data from animals

435 in which the transgene expression and/or fiber was located outside the targeted area were

436 excluded from analysis. Five out of 10 mice were excluded due to improper targeting of fiber or 437 viral injection.

439 Body composition analysis

440 Determination of body fat and lean mass was performed using quantitative magnetic resonance 441 spectroscopy (EchoMRI ${ }^{\mathrm{TM}}$, Houston, TX) in conscious mice using the NIDDK-funded Nutrition 442 Obesity Research Center Energy Balance Core (Taicher, et al., 2003).

\section{Indirect calorimetry}

445 For indirect calorimetry studies, C57BI/6 mice were acclimated to metabolic cages after which 446 energy expenditure was measured using a computer-controlled indirect calorimetry system 447 (Promethion® ${ }^{\circledR}$, Sable Systems, Las Vegas, NV) as described (Kaiyala et al., 2015; 2012; Kaiyala, 448 et al., 2016). For each animal, $\mathrm{O}_{2}$ consumption and $\mathrm{CO}_{2}$ production were measured for $1 \mathrm{~min}$ at 449 5-min (acute studies) or 10-min (chronic studies) intervals. Respiratory quotient (RQ) was 450 calculated as the ratio of $\mathrm{CO}_{2}$ production to $\mathrm{O}_{2}$ consumption. Energy expenditure was calculated 451 from $\mathrm{VO}_{2}$ and $\mathrm{VCO}_{2}$ data using the Weir equation (Weir, et al., 1949). Ambulatory activity was 452 measured continuously with consecutive adjacent infrared beam breaks in the $x-, y-$ and $z$-axes 453 were scored as an activity count that was recorded every 5 or $10 \mathrm{~min}$. Data acquisition and 
454 instrument control were coordinated by MetaScreen v.1.6.2 and raw data was processed using

455 ExpeData v.1.4.3 (Sable Systems) using an analysis script documenting all aspects of data

456 transformation.

\section{Core body temperature monitoring}

459 Adult male C57BI/6 mice received body temperature transponders implanted into the peritoneal

460 cavity (Starr Life Science Corp, Oakmont, PA) and were allowed a one-week recovery period.

461 Animals were then acclimated to metabolic cages enclosed in temperature- and humidity-

462 controlled cabinets (Caron Products and Services, Marietta, $\mathrm{OH}$ ) prior to study. Signals emitted

463 by body-temperature transponders were sensed by a platform receiver positioned underneath the

464 cage and analyzed using VitalView software as described (Kaiyala, et al., 2015; Kaiyala, et al., 465 2016).

\section{Immunohistochemistry}

468 For immunohistochemical studies, animals were overdosed with ketamine:xylazine and perfused

469 with $1 \mathrm{X}$ phosphate-buffered saline (PBS) followed by $4 \%(\mathrm{v} / \mathrm{v})$ paraformaldehyde in $0.1 \mathrm{M}$ PBS.

470 Brains were removed and post-fixed for $4 \mathrm{hr}$ in paraformaldehyde followed by sucrose $(30 \%)$

471 dehydration and embedding in OCT blocks. Free-floating coronal sections were obtained via

472 Cryostat at $35-\mu \mathrm{m}$ thickness and stored in $1 \mathrm{X}$ PBS with $0.02 \%$ sodium azide at $4^{\circ} \mathrm{C}$. Free-floating

473 sections were then washed at room temperature in phosphate-buffered saline with $0.1 \%$ Tween

47420 or $0.4 \%$ Triton-X 100 (PBS-T) for one hour, followed by a blocking buffer (5\% normal donkey

475 serum, $1 \%$ bovine serum albumin in $0.1 \mathrm{M}$ PBS-T with $0.01 \%$ sodium azide) for an additional hour

476 with rocking. Sections were then incubated $24-48 \mathrm{hr}$ at $4^{\circ} \mathrm{C}$ with polyclonal rabbit anti-cFos (Ab-5

477 (4-17), 1:10,000, RRID:AB_2106755; Millipore, Burlington, MA) and/or Chicken anti-GFP

478 (Abcam, ab13970, 1:10,000, RRID:AB_300798; Cambridge, UK) in blocking buffer, followed by

479 PBS-T washes at room temperature. Sections were then incubated in secondary donkey anti- 
480 rabbit Alexa 594 or donkey anti-chicken Alexa 488 (1:500, Jackson ImmunoResearch

481 Laboratories, West Grove, PA) in blocking buffer overnight at $4^{\circ} \mathrm{C}$, followed by PBS-T washes.

482 Sections were stained with DAPI (1:10,000, Sigma, St. Louis, MO) for 30 minutes, followed by a

483 final set of washes and mounting with Fluoromount-G (Thermo Fisher Scientific, Wilmington, DE)

484 or prepared polyvinyl acetate (PVA).

485

486 qRT-PCR

487 To quantify specific hypothalamic mRNA transcripts, mice were sacrificed at study completion

488 and the hypothalamus rapidly dissected and flash frozen. Individual tissue samples were dounce-

489 homogenized and RNA was isolated using Qiagen RNeasy Micro Kit (Kit\# 74004, Hilden,

490 Germany) and isolated RNA concentrations were quantified by Nanodrop (Thermo Fisher

491 Scientific, Wilmington, DE). qRT-PCR was performed using SYBR Green One-Step (Kit\# 600825,

492 Agilent, Santa Clara, CA). qRT-PCR data were analyzed using the Sequence Detection System

493 software (SDS Version 2.2; Applied Biosystems, Foster City, CA). Expression levels of each gene

494 were normalized to a housekeeping gene (18S RNA) and standard curve. Non-template controls

495 were incorporated into each PCR run. Oligonucleotides selected were: Agouti-related peptide

496 (Agrp): For: 5'-ATGCTGACTCGAATGTTGCTG-3', Rev: 5'-CAGACTTAGACCTGGGAACTCT-3',

497 Pro-opiomelanocortin (Pomc): For: 5'-CAGTGCCAGGACCTCAC-3', Rev: 5'-

498 CAGCGAGAGGTCGAGTTTG-3', Neuropeptide Y (Npy): For: 5'-CTCCGCTCTGCGACACTAC-

499 3', Rev: 5'-AGGGTCTTCAAGCCTTGTTCT-3', Pro-melanin concentrating hormone (Pmch): For:

500 5'-GAATTTGGAAGATGACATAGTAT-3', Rev: 5'-CCTGAGCATGTCAAAATCTCTCC-3', 18S

501 Ribosomal RNA (18S): For: 5'-CGGACAGGATTGACAGATTG-3', Rev: 5'-

502 CAAATCGCTCCACCAACTAA-3'.

503

$504 \quad$ Fiber photometry 
505 Mice expressing GCaMP6s in AgRP neurons were connected to a fiber-photometry system to

506 enable fluorometric analysis of real-time neuronal activity. Briefly, for calcium recording in vivo,

507 two excitation wavelengths (470 nm and $405 \mathrm{~nm}$ isosbestic) were used to indicate calcium-

508 dependent and calcium-independent (i.e., due to bleaching and motion artifacts) GCaMP6s

509 fluorescence, respectively. Light was delivered via fiber-coupled LEDs (LED lights: M470F3 and

510 M405FP1, LED driver: DC4104, Thorlabs, Newton, NJ) and modulated by a real-time amplifier

511 (RZ5P, Tucker-Davis Technology (TDT), Alachua, FL) at non-divisible frequencies (331 Hz and

$512231 \mathrm{~Hz}$, respectively) to prevent signal interference between the channels. Excitation lights were

513 bandpass filtered (475 \pm 15nm , $405 \pm 5 \mathrm{~nm}$; iFMC4, Doric Lenses, Quebec, QC, Canada) and the

514 combined excitation light delivered through a fiberoptic patch cord (M75L01, Thorlabs) connected

515 to a rotary joint (FRJ, $0.48 \mathrm{NA}, \varnothing 400 \mu \mathrm{m}$ core; Doric Lenses) to prevent fiberoptic torsion during

516 animal movement. A final connector patch cord (MFP, 0.48 NA, $\varnothing 400 \mu \mathrm{m}$ core; Doric Lenses)

517 was connected to the implanted fiberoptic via a ceramic mating sleeve (ADAL1, Thorlabs).

518 Emitted light was collected through the same patch cord, bandpass filtered (525 \pm 25 nm; iFMC4)

519 and transduced to digital signals by an integrated photodetector head. Electrical signals were

520 sampled at a rate of $1017.25 \mathrm{~Hz}$ and demodulated by the RZ5P real-time processor. Experiments

521 were controlled by Synapse software (TDT).

522 Custom MATLAB scripts were developed for analyzing fiber photometry data. The

523 isosbestic 405-nm excitation control signal was subtracted from the 470-nm excitation signal to

524 remove movement artifacts from intracellular calcium dependent GCaMP6s fluorescence.

525 Baseline drift was evident in the signal due to slow photobleaching artifacts, particularly during

526 the first several minutes of each recording session. A double exponential curve was fit to the raw

527 trace of temperature-ramping experiments while a linear fit was applied to the raw trace of food

528 presentation experiments and subtracted to correct for baseline drift. After baseline correction,

$529 \mathrm{dF} / \mathrm{F}$ was calculated as individual fluorescence intensity measurements relative to median

530 fluorescence of entire session for $470 \mathrm{~nm}$ channel and Z-score normalized. Z-score normalized 
$531 \mathrm{dF} / \mathrm{F}$ for each temperature $\left(30\right.$ or $\left.14^{\circ} \mathrm{C}\right)$ were limited to the 10 -min period either before or after

532 the 1 -min ramp either between the $14^{\circ} \mathrm{C}$ to $30^{\circ} \mathrm{C}$ transition or the $30^{\circ} \mathrm{C}$ to $14^{\circ} \mathrm{C}$ transition.

\section{Measuring determinants of energy balance}

535 To examine the effect of chronic mild, cold exposure on comprehensive measures of energy 536 homeostasis, mice were acclimated to metabolic cages housed within temperature- and humidity537 controlled chambers, and either remained at $22^{\circ} \mathrm{C}$ or they were exposed to $14^{\circ} \mathrm{C}$ for 5 days. 538 During this period, continuous measures of energy expenditure, respiratory quotient, ambulatory 539 activity and energy and water intake were recorded, and body composition was determined both 540 before and after the thermogenic challenge.

541 To examine the effect of acute changes in ambient temperature on energy intake, wild-

542 type mice (mean BW: $24.59 \pm 0.31 \mathrm{~g}$ ) were acclimated to metabolic cages housed within

543 temperature- and humidity-controlled chambers. One-hour fasted mice were placed directly into 544 metabolic cages housed within environmental chambers that were pre-set overnight at either $54522^{\circ} \mathrm{C}$ or $14^{\circ} \mathrm{C}$ at 10 am for $24 \mathrm{hr}$ for continuous measures of energy expenditure, respiratory 546 quotient, ambulatory activity and energy intake. Animals were studied using a randomized cross547 over design in which housing conditions were separated by at least $72 \mathrm{hr}$, with each animal 548 serving as its own control.

$550 \quad$ Measuring Fos induction

551 To determine whether acute cold exposure induces Fos in AgRP neurons, sated AgRP-Cre:GFP 552 mice were housed in temperature-controlled chambers pre-set overnight at either $22^{\circ} \mathrm{C}, 30^{\circ} \mathrm{C}$, or $55314^{\circ} \mathrm{C}$ for $90 \mathrm{~min}$. Although food is typically removed during the period prior to Fos quantitation in 554 this type of study (so as to minimize the impact that variation in food intake can have on the activity 555 of AgRP neurons), we opted not to do so here, based on the concern that cold-exposed mice 556 would experience a state of negative energy balance greater than occurred in controls housed at 
557 room temperature (owing to a comparatively greater rate of energy expenditure), and that this

558 might confound data interpretation. Animals were then anesthetized and perfused as described

559 below. Immunostaining for Fos was quantified by imaging at either 10X or 20X on a Leica SP8X

560 confocal system with support from the University of Washington, W.M. Keck Microscopy Center.

561 Images were merged using ImageJ (Fiji, NIH) and threshold adjusted to minimize nonspecific

562 background fluorescence. Fos + cells were then identified and counted in 35- $\mu \mathrm{m}$ sections obtained

563 serially across the full rostral to caudal axis of the arcuate nucleus using the 'analyze particles'

564 feature, such that consistent fluorescence and size thresholds were used throughout, as

565 previously described (Faber, et al., 2018). For measures of Fos induction in additional

566 thermoregulatory nuclei, 2-3 sections from each region were counted for each subject.

\section{Measuring AgRP-neuron activity}

569 To assess the impact of cold exposure on AgRP-neuronal activity, mice were acutely housed on

570 a custom thermal platform. Baseline GCaMP6s fluorescence signals was set to similar levels

571 across animals by adjusting the intensities of the 470-nm and 405-nm LEDs, and baseline

572 recording was measured for $5 \mathrm{~min}$. For temperature-challenge studies, mice were placed in a

573 small custom-built plexiglass temperature chamber ( 3 " $\times 6$ " $\times 6$ ") that was constructed to enclose

574 a Peltier cooler platform that could be controlled by an external controller (TE Tech, TC720) as

575 described (Tan, et al., 2016). Animals were acclimated on 3 separate days to tether and Peltier

576 platform. For temperature ramp studies, animals were attached to tether and allowed 2-3 min for

577 photobleaching before photometry recording is initiated. Temperature-ramp studies were

578 designed to test GCaMP6s activity in AgRP neurons when transitioning from $30^{\circ} \mathrm{C}$ to $14^{\circ} \mathrm{C}$ or

$57914^{\circ} \mathrm{C}$ to $30^{\circ} \mathrm{C}$. Animals were held at $30^{\circ} \mathrm{C}$ for $10 \mathrm{~min}$ before transitioning to $14^{\circ} \mathrm{C}$ for 10 min before

580 returning to $30^{\circ} \mathrm{C}$ with each temperature ramp repeated twice during a recording session.

581 Transitions between temperatures were all set to $60 \mathrm{~s}$. Experiments were aligned to initial $22^{\circ} \mathrm{C}$. 
582 As an added positive control, at the end of each study, animals were presented with a food pellet,

583 which, led to an expected reduction in AgRP-neuron activity.

585 Prior to study, mice were acclimated to experimental procedures and AgRP-calcium responses

586 to food presentation in a fast-refeed paradigm was used as a positive control to indicate

587 successfully targeted animals. Briefly, overnight-fasted animals that failed to demonstrate $\geq 10 \%$

588 reduction in $\Delta \mathrm{F} / \mathrm{F}$ in response to chow presentation were identified as surgical misses and

589 excluded from further study; post hoc IHC validated poor viral expression and/or fiber-optic

590 placement in these animals.

\section{Cold-induced activation of AgRP neurons}

593 To determine whether activation of AgRP neurons is required for cold-induced hyperphagia,

594 AgRP-IRES-Cre mice (mean BW: $36.10 \pm 1.06 \mathrm{~g}$ ) received a bilateral microinjection of the 595 inhibitory DREADD (hM4Di) directed to the ARC. After 3 weeks for recovery from surgery, 596 acclimation to injection/handling, and expression of the transgene, animals were acclimated to 597 environmental chambers to minimize stress. On the day prior to the experiment, animals were 598 returned to their previous home cage and the environmental chambers were allowed $16 \mathrm{hr}$ to 599 come to temperature $\left(30^{\circ} \mathrm{C}, 22^{\circ} \mathrm{C}\right.$, or at $\left.14^{\circ} \mathrm{C}\right)$. On the experimental day, food was removed at 9

$600 \mathrm{AM}$ and mice received a pre-treatment injection of either $\mathrm{CNO}(1 \mathrm{mg} / \mathrm{kg}$, ip) or saline in a 601 randomized cross-over manner. At 10AM, mice were placed into metabolic cages housed within 602 environmental chambers set at either $30^{\circ} \mathrm{C}, 22^{\circ} \mathrm{C}$, or $14^{\circ} \mathrm{C}$ with continuous measures of energy 603 intake and energy expenditure recorded over a 4-hr period.

\section{Statistics}

606 Results are expressed as mean \pm SEM. Significance was established at $p<0.05$, two-tailed. For 607 statistical comparisons involving core temperature, energy expenditure, ambulatory activity, 
608 respiratory quotient or energy intake, data obtained during chronic cold exposure $\left(14^{\circ} \mathrm{C}\right)$ relative

609 to room temperature $\left(22^{\circ} \mathrm{C}\right)$ were reduced into average light and dark photoperiods for each

610 mouse. A group by ambient temperature ANOVA with least significance difference pairwise tests

611 compared mean values between groups. Where applicable, time-series data were analyzed

612 using treatment by time-mixed factorial ANOVA or linear-mixed model analysis controlling for

613 within subjects correlated data using a random intercept model with treatment and time as fixed

614 effects (Fitzmaurice, et al., 2012). All post hoc comparisons following one-way ANOVA were

615 determined using Sidak correction for multiple comparisons. A two-sample unpaired Student's t-

616 test was used for two-group comparisons and a paired t-test for within group comparisons.

617 Statistical analyses were performed using Statistica (version 7.1; Statsoft, Incl, Tulsa, OK), SPSS

618 (SPSS version 23, IBM Corp., Somers, NY), R (v 3.6.2, R Core Team 2016), GraphPad Prism

619 (version 7.0; La Jolla, CA), and MATLAB (Mathworks; Natick, MA)

620 (https://github.com/christianepedersen/Cold Hyperphagia Requires AGRP).

\section{Acknowledgments}

623 The authors gratefully acknowledge Dr. Larry Zweifel (University of Washington) for providing the

624 inhibitory DREADD virus. This work was supported by National Institutes of Health Grants

625 DK089056 (to G.J.M.), DK083042 and DK101997 (to M.W.S.), R37DA033396 (to M.R.B.), R01-

626 DA-24908 (to R.D.P), the NAPE Center Imaging and Circuits Core (P30 DA048736), the

627 University of Washington W.M. Keck Microscopy Center (S10 OD016240), the Nutrition Obesity

628 Research Center (DK035816), the Diabetes Research Center (DK17047), F31 DK113673 and

629 T32 GM095421 (to C.L.F.), and the Nutrition, Obesity and Atherosclerosis Training Grant (T32

630 HL007028) at the University of Washington (to J.D.D.), a Dick and Julia McAbee Endowed

631 Fellowship (to J.D.D.) and a American Diabetes Association Innovative Basic Science Award

632 (ADA 1-19-IBS-192, to G.J.M.) and Fellowship Grant (ADA 1-19-PDF-103, to J.D.D.). 


\section{Competing interests:}

635 The authors declare that no competing interests exist.

636

\section{Author Contributions}

638 Conceptualization was performed by J.D.D., J.M.S., M.W.S and G.J.M. Data curation was

639 performed by J.D.D., B.P., J.T.N., M.A.T., and G.J.M. Funding acquisition was performed by

640 J.D.D, J.M.S., M.W.S., and G.J.M. Formal analysis was performed by J.D.D., C.P., K.J.K. and

641 G.J.M. Methodology was performed by J.D.D., C.L.F., C.P., S.A.L., K.O., R.D.P., and G.J.M.

642 Project administration was performed by J.D.D. and G.J.M. Validation was performed by J.D.D.,

643 B.P., and V.D. Writing - review and editing - was performed by J.D.D., C.L.F., J.M.S., R.D.P.,

644 M.R.B., M.W.S., and G.J.M. 


\section{REFERENCES}

646

647

648

649

650

651

652

653

654

655

656

657

658

659

660

661

662

663

664

665

666

667

668

669

670

671

672

673

674

675

676

677

678

679

680

681

682

683

684

685

686

687

688

689

690

691

692

693

694

Abreu-Vieira, G., Xiao, C., Gavrilova, O., \& Reitman, M. L. (2015). Integration of body temperature into the analysis of energy expenditure in the mouse. Molecular Metabolism, 4(6), 461-470. http://doi.org/10.1016/j.molmet.2015.03.001

Aponte, Y., Atasoy, D., \& Sternson, S. M. (2010). AGRP neurons are sufficient to orchestrate feeding behavior rapidly and without training. Nature Publishing Group, 14(3), 351-356. http://doi.org/10.1038/nn.2739

Armitage, G., Harris, R. B., Hervey, G. R., \& Tobin, G. (1984). The relationship between energy expenditure and environmental temperature in congenitally obese and non-obese Zucker rats. The Journal of Physiology, 350(1), 197-207. http://doi.org/10.1113/jphysiol.1984.sp015196

Atasoy, D., Betley, J. N., Su, H. H., \& Sternson, S. M. (2012). Deconstruction of a neural circuit for hunger. Nature, 488(7410), 172-177. http://doi.org/10.1038/nature11270

Betley, J. N., Xu, S., Cao, Z. F. H., Gong, R., Magnus, C. J., Yu, Y., \& Sternson, S. M. (2015). Neurons for hunger and thirst transmit a negative-valence teaching signal. Nature, 521(7551), 180-185. http://doi.org/10.1038/nature14416

Bing, C., Frankish, H. M., Pickavance, L., Wang, Q., Hopkins, D. F., Stock, M. J., \& Williams, G. (1998). Hyperphagia in cold-exposed rats is accompanied by decreased plasma leptin but unchanged hypothalamic NPY. The American Journal of Physiology, 274(1 Pt 2), R62-8.

Bratincsák, A., \& Palkovits, M. (2004). Activation of brain areas in rat following warm and cold ambient $\quad$ exposure. Neuroscience, $127(2), \quad 385-397$. http://doi.org/10.1016/j.neuroscience.2004.05.016

Cannon, B., \& Nedergaard, J. (2004). Brown adipose tissue: function and physiological significance. Physiological Reviews, 84(1), 277-359. http://doi.org/10.1152/physrev.00015.2003

Cannon, B., \& Nedergaard, J. (2010). Nonshivering thermogenesis and its adequate measurement in metabolic studies, 214(2), 242-253. http://doi.org/10.1242/jeb.050989

Chen, T.-W., Wardill, T. J., Sun, Y., Pulver, S. R., Renninger, S. L., Baohan, A., Schreiter, E.R., Kerr, R.A., Orger, M.B., Jayaraman, V., Looger, L.L., Svoboda, K., \& Kim, D. (2013). Ultrasensitive fluorescent proteins for imaging neuronal activity. Nature, 499(7458), 95-300. http://doi.org/10.1038/nature12354

Chen, Y., \& Knight, Z. A. (2016). Making sense of the sensory regulation of hunger neurons, 38(4), 316-324. http://doi.org/10.1002/bies.201500167

Chen, Y., Essner, R. A., Kosar, S., Miller, O. H., Lin, Y.-C., Mesgarzadeh, S., \& Knight, Z. A. (2019). Sustained NPY signaling enables AgRP neurons to drive feeding. eLife, 8, 757. http://doi.org/10.7554/eLife.46348

Ellacott, K. L. J., Morton, G. J., Woods, S. C., Tso, P., \& Schwartz, M. W. (2010). Perspective. Cell Metabolism, 12(1), 10-17. http://doi.org/10.1016/j.cmet.2010.06.001

Faber, C. L., Matsen, M. E., Velasco, K. R., Damian, V., Phan, B. A., Adam, D., Therattil, A., Schwartz, M. W., \& Morton, G.J. (2018). Distinct Neuronal Projections from the Hypothalamic Ventromedial Nucleus Mediate Glycemic and Behavioral Effects. Diabetes, 67(12), 25182529. http://doi.org/10.2337/db18-0380

Fitzmaurice, G. M., Laird, N. M., \& Ware, J. H. (2012). Applied Longitudinal Analysis. John Wiley \& Sons.

Franklin, K. B. J., \& Paxinos, G. (2013). Paxinos and Franklin's The mouse brain in stereotaxic coordinates.

Garfield, A. S., Shah, B. P., Burgess, C. R., Li, M. M., Li, C., Steger, J. S., Madara, J. C., Campbell, J. N., Kroeger, D., Scammel, T. E., Tannous, B. A., Myers, M. G., Andermann, M. L., Krashes, M. J., \& Lowell, B. B. (2016). Dynamic GABAergic afferent modulation of AgRP neurons. Nature Neuroscience, 1-12. http://doi.org/10.1038/nn.4392 
695

696

697

698

699

700

701

702

703

704

705

706

707

708

709

710

711

712

713

714

715

716

717

718

719

720

721

722

723

724

725

726

727

728

729

730

731

732

733

734

735

736

737

738

739

740

741

742

743

744

Geerling, J. C., Kim, M., Mahoney, C. E., Abbott, S. B. G., Agostinelli, L. J., Garfield, A. S., Krashes, M. J., Lowell, B. B. \& Scammel, T. E. (2016). Genetic identity of thermosensory relay neurons in the lateral parabrachial nucleus, 310(1), R41-R54. http://doi.org/10.1152/ajpregu.00094.2015

Gordon, C. J. (1993). Temperature regulation in laboratory rodents. New York, Cambridge University Press.

Hahn, T. M., Breininger, J. F., Baskin, D. G., \& Schwartz, M. W. (1998). Coexpression of Agrp and NPY in fasting-activated hypothalamic neurons. Nature Neuroscience, 1(4), 271-272. http://doi.org/10.1038/1082

Hardie, L. J., Rayner, D. V., Holmes, S., \& Trayhurn, P. (1996). Circulating leptin levels are modulated by fasting, cold exposure and insulin administration in lean but not Zucker (fa/fa) rats as measured by ELISA. Biochemical and Biophysical Research Communications, 223(3), 660-665. http://doi.org/10.1006/bbrc.1996.0951

Hunt, J. L., Zaretsky, D. V., Sarkar, S., \& DiMicco, J. A. (2009). Dorsomedial hypothalamus mediates autonomic, neuroendocrine, and locomotor responses evoked from the medial preoptic area. AJP: Regulatory, Integrative and Comparative Physiology, 298(1), R130R140. http://doi.org/10.1152/ajpregu.00574.2009

Johnson, R. E., \& Kark, R. M. (1947). Environment and Food Intake in Man. Science, 105(2728), 378-379. http://doi.org/10.1126/science.105.2728.378

Kaiyala, K. J., Morton, G. J., Thaler, J. P., Meek, T. H., Tylee, T., Ogimoto, K., \& Wisse, B. E. (2012). Acutely Decreased Thermoregulatory Energy Expenditure or Decreased Activity Energy Expenditure Both Acutely Reduce Food Intake in Mice. PLoS ONE, 7(8), e41473-13. http://doi.org/10.1371/journal.pone.0041473

Kaiyala, K. J., Ogimoto, K., Nelson, J. T., Muta, K., \& Morton, G. J. (2016). Physiological role for leptin in the control of thermal conductance. Molecular Metabolism, 5(10), 892-902. http://doi.org/10.1016/j.molmet.2016.07.005

Kaiyala, K. J., Ogimoto, K., Nelson, J. T., Schwartz, M. W., \& Morton, G. J. (2015). Leptin signaling is required for adaptive changes in food intake, but not energy expenditure, in response to different thermal conditions. PLoS ONE, 10(3), e0119391. http://doi.org/10.1371/journal.pone.0119391

Kovács, K. J. (1998). c-Fos as a transcription factor: a stressful (re)view from a functional map. Neurochemistry International, 33(4), 287-297. http://doi.org/10.1016/s0197-0186(98)000230

Krashes, M. J., Koda, S., Ye, C., Rogan, S. C., Adams, A. C., Cusher, D. S., Maratos-Flier, E., Roth, F. L. \& Lowell, B. B. (2011). Rapid, reversible activation of AgRP neurons drives feeding behavior in mice. Journal of Clinical Investigation, 121(4), 1424-1428. http://doi.org/10.1172/JCl46229DS1

Krashes, M. J., Shah, B. P., Madara, J. C., Olson, D. P., Strochlic, D. E., Garfield, A. S., Vong, L., Pef, H., Watabe-Uchida, M., Uchida, N., Liberles, S. D. \& Lowell, B. B. (2014). An excitatory paraventricular nucleus to AgRP neuron circuit that drives hunger. Nature, 507(7491), 238242. http://doi.org/10.1038/nature12956

Livneh, Y., Ramesh, R. N., Burgess, C. R., Levandowski, K. M., Madara, J. C., Fenselau, H., Goldey, G. J., Diaz, V. E., Jikomes, N., Resch, J. M., Lowell, B. B. \& Andermann, M. L. (2017). Homeostatic circuits selectively gate food cue responses in insular cortex. Nature, 546(7660), 611-616. http://doi.org/10.1038/nature22375

Lowell, B. B. (2019). New Neuroscience of Homeostasis and Drives for Food, Water, and Salt. New England Journal of Medicine, 380(5), 459-471. http://doi.org/10.1056/NEJMra1812053

Madden, C. J., \& Morrison, S. F. (2019). Central nervous system circuits that control body temperature. Neuroscience Letters, 696, 225-232. http://doi.org/10.1016/j.neulet.2018.11.027 
Mandelblat-Cerf, Y., Ramesh, R. N., Burgess, C. R., Patella, P., Yang, Z., Lowell, B. B., \& Andermann, M. L. (2015). Arcuate hypothalamic AgRP and putative POMC neurons show opposite changes in spiking across multiple timescales. eLife, 4. http://doi.org/10.7554/eLife.07122

McCarthy, H. D., Kilpatrick, A. P., Trayhurn, P., \& Williams, G. (1993). Widespread increases in regional hypothalamic neuropeptide $Y$ levels in acute cold-exposed rats. Nsc, 54(1), 127132. http://doi.org/10.1016/0306-4522(93)90388-v

Meek, T. H., Nelson, J. T., Matsen, M. E., Dorfman, M. D., Guyenet, S. J., Damian, V., Allison, M. B., Scarlett, J. M., Nguyen, H. T., Thaler, J. P., Olson, D. P., Myers, M. G., Schwartz, M. W. \& Morton, G. J. (2016). Functional identification of a neurocircuit regulating blood glucose. Proceedings of the National Academy of Sciences, 113(14), E2073-82. http://doi.org/10.1073/pnas.1521160113

Morrison, S. F., Madden, C. J., \& Tupone, D. (2014). Central Neural Regulation of Brown Adipose Tissue Thermogenesis and Energy Expenditure. Cell Metabolism, 19(5), 741-756. http://doi.org/10.1016/j.cmet.2014.02.007

Nakamura, K., \& Morrison, S. F. (2011). Central efferent pathways for cold-defensive and febrile shivering. The Journal of Physiology, 589(14), 3641-3658. http://doi.org/10.1113/jphysiol.2011.210047

Puerta, M., Abelenda, M., Rocha, M., \& Trayhurn, P. (2002). Effect of acute cold exposure on the expression of the adiponectin, resistin and leptin genes in rat white and brown adipose tissues. Hormone and Metabolic Research = Hormon- Und Stoffwechselforschung = Hormones Et Metabolisme, 34(11-12), 629-634. http://doi.org/10.1055/s-2002-38252

Ravussin, Y., Xiao, C., Gavrilova, O., \& Reitman, M. L. (2014). Effect of Intermittent Cold Exposure on Brown Fat Activation, Obesity, and Energy Homeostasis in Mice. PLoS ONE, 9(1), e85876-9. http://doi.org/10.1371/journal.pone.0085876

Rezai-Zadeh, K., \& Münzberg, H. (2013). Physiology \& Behavior. Physiology \& Behavior, 121(C), 49-55. http://doi.org/10.1016/j.physbeh.2013.02.014

Ricci, M. R., Fried, S. K., \& Mittleman, K. D. (2000). Acute cold exposure decreases plasma leptin in women. Metabolism, 49(4), 421-423. http://doi.org/10.1016/s0026-0495(00)80001-3

Sanz, E., Quintana, A., Deem, J. D., Steiner, R. A., Palmiter, R. D., \& McKnight, G. S. (2015). Fertility-Regulating Kiss1 Neurons Arise from Hypothalamic Pomc-Expressing Progenitors. Journal of Neuroscience, 35(14), 5549-5556. http://doi.org/10.1523/JNEUROSCI.361414.2015

Schwartz, M. W., Seeley, R. J., Zeltser, L. M., Drewnowski, A., Ravussin, E., Redman, L. M., \& Leibel, R. L. (2017). Obesity Pathogenesis: An Endocrine Society Scientific Statement. Endocrine Reviews, 38(4), 267-296. http://doi.org/10.1210/er.2017-00111

Schwartz, M. W., Woods, S. C., Porte, D., Seeley, R. J., \& Baskin, D. G. (2000). Central nervous system control of food intake. Nature, 404(6778), 661-671. http://doi.org/10.1038/35007534

Smith, C. K., \& Romsos, D. R. (1984). Cold acclimation of obese (ob/ob) mice: effects of energy balance. Metabolism, 33(9), 853-857. http://doi.org/10.1016/0026-0495(84)90114-8

Sohn, J.-W., Elmquist, J. K., \& Williams, K. W. (2013). Neuronal circuits that regulate feeding behavior and metabolism. Trends in Neurosciences, 36(9), 504-512. http://doi.org/10.1016/j.tins.2013.05.003

Taicher, G. Z., Tinsley, F. C., Reiderman, A., \& Heiman, M. L. (2003). Quantitative magnetic resonance (QMR) method for bone and whole-body-composition analysis. Analytical and Bioanalytical Chemistry, 377(6), 990-1002. http://doi.org/10.1007/s00216-003-2224-3

Tan, C. L., \& Knight, Z. A. (2018). Regulation of Body Temperature by the Nervous System. Neuron, 98(1), 31-48. http://doi.org/10.1016/j.neuron.2018.02.022

Tan, C. L., Cooke, E. K., Leib, D. E., Lin, Y.-C., Daly, G. E., Zimmerman, C. A., \& Knight, Z. A. (2016). Warm-Sensitive Neurons that Control Body Temperature. Cell, 1-29. http://doi.org/10.1016/j.cell.2016.08.028 
Tang, G.-B., Cui, J.-G., \& Wang, D.-H. (2009). Role of hypoleptinemia during cold adaptation in Brandt's voles (Lasiopodomys brandtii). American Journal of Physiology-Regulatory, Integrative and Comparative Physiology, 297(5), R1293-301. http://doi.org/10.1152/ajpregu.00185.2009

Thurlby, P. L., \& Trayhurn, P. (1979). The role of thermoregulatory thermogenesis in the development of obesity in genetically-obese (ob/ob) mice pair-fed with lean siblings. The British Journal of Nutrition, 42(3), 377-385. http://doi.org/10.1079/bjn19790127

Timper, K., \& Brüning, J. C. (2017). Hypothalamic circuits regulating appetite and energy homeostasis: pathways to obesity, 10(6), 679-689. http://doi.org/10.1242/dmm.026609

Vallerand, A. L., Lupien, J., \& Bukowiecki, L. J. (1986). Cold Exposure Reverses the Diabetogenic Effects of High-Fat Feeding. Diabetes, 35(3), 329-334. http://doi.org/10.2337/diab.35.3.329

Varela, L., \& Horvath, T. L. (2012). Leptin and insulin pathways in POMC and AgRP neurons that modulate energy balance and glucose homeostasis. EMBO Reports, 13(12), 1079-1086. http://doi.org/10.1038/embor.2012.174

Weir, J. B. D. B. (1949). New methods for calculating metabolic rate with special reference to protein metabolism. The Journal of Physiology, 109(1-2), 1-9. http://doi.org/10.1113/jphysiol.1949.sp004363

Xu, Y., Elmquist, J. K., \& Fukuda, M. (2011). Central nervous control of energy and glucose balance: focus on the central melanocortin system. Annals of the New York Academy of Sciences, 1243(1), 1-14. http://doi.org/10.1111/j.1749-6632.2011.06248.x

Zimmer, M. R., Fonseca, A. H. O., Iyilikci, O., Pra, R. D., \& Dietrich, M. O. (2019). Functional Ontogeny of Hypothalamic AgRP Neurons in Neonatal Mouse Behaviors. Cell, 178(1), 4459.e7. http://doi.org/10.1016/j.cell.2019.04.026 

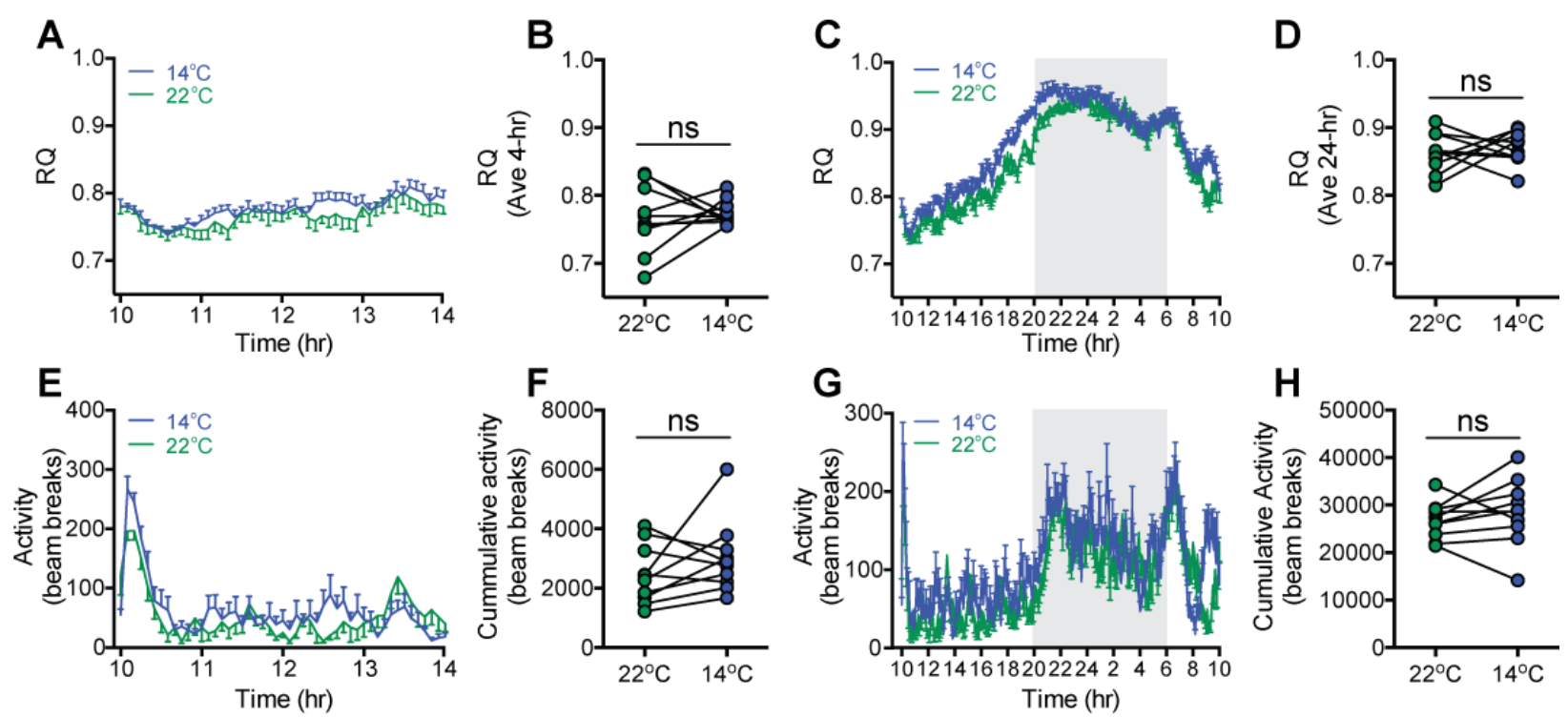

Supplemental Figure 1 (Related to Figure 2). Effect of acute mild cold exposure on respiratory quotient and ambulatory activity

(A, C) Time-series and (B, D) mean respiratory quotient (RQ) over 4-hr and 24-hr, respectively, and $(\mathbf{E}, \mathbf{G})$ time-series and $(\mathbf{F}, \mathbf{H})$ total ambulatory activity over 4-hr and 24-hr, respectively, in adult male wild-type mice moved into housing at either $14^{\circ} \mathrm{C}$ or $22^{\circ} \mathrm{C}$ beginning at 10:00 AM,

832 $\mathrm{n}=10 /$ group, mean \pm SEM.

833 

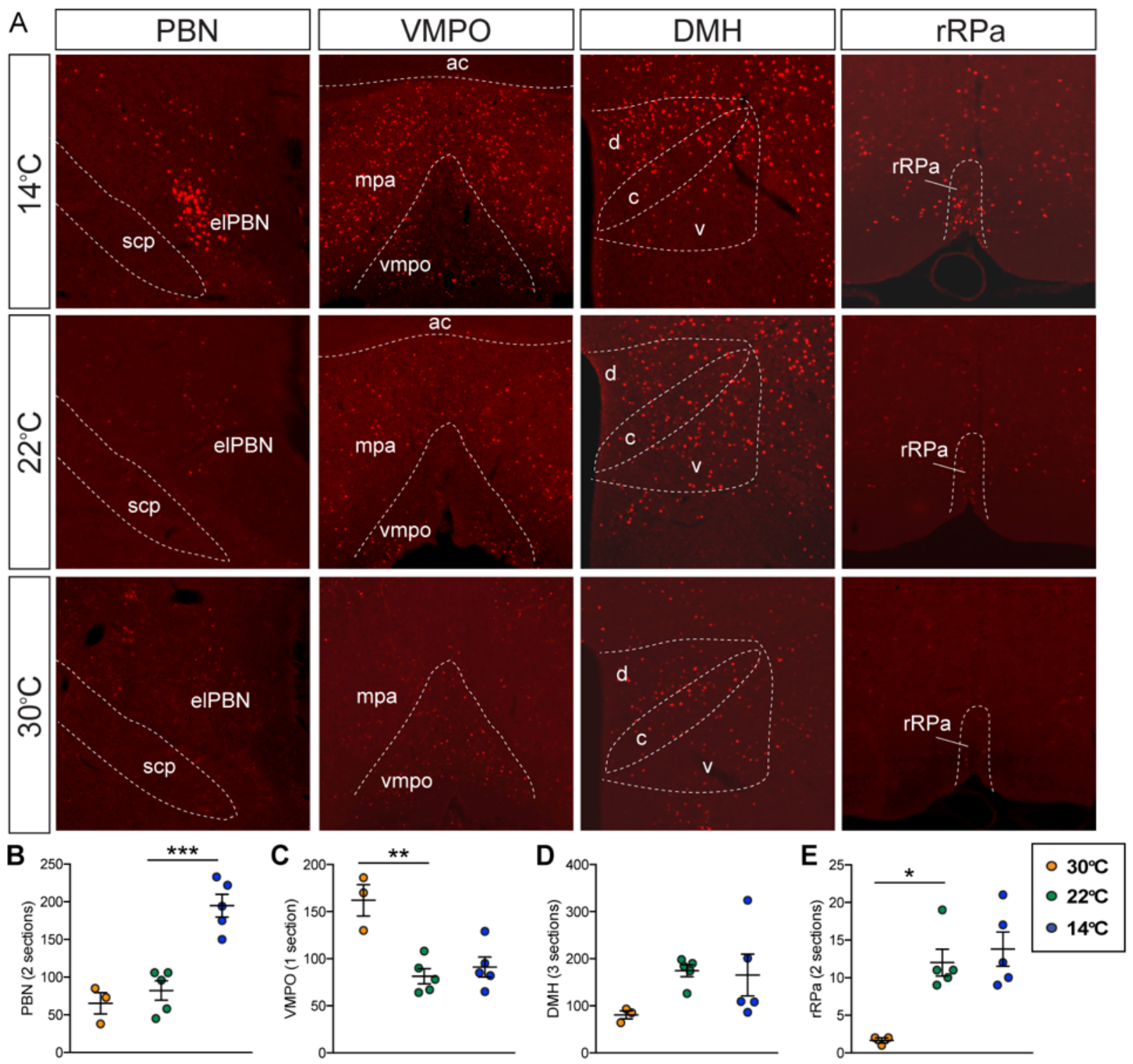

\section{Supplemental Figure 2 (Related to Figure 3). Fos induction in known thermoregulatory brain regions}

(A) Representative images of Fos induction in known thermoregulatory brain regions. Quantification of Fos induction in (B) parabrachial nucleus (PBN), (C) ventromedial preoptic area (VMPO) and medial preoptic area (MPA), (D) dorsomedial hypothalamus (DMH) and (E) rostral raphe pallidus ( $\mathrm{rRPa}$ ) following 90 -min of exposure to either $30^{\circ} \mathrm{C}$, or $22^{\circ} \mathrm{C}$ or $14^{\circ} \mathrm{C}, \mathrm{n}=3$-5/group. Mean \pm SEM, One-way ANOVA, ${ }^{* * *} p<0.001,{ }^{* *} p<0.01,{ }^{*} p<0.05$ vs. $22^{\circ} \mathrm{C}$. 

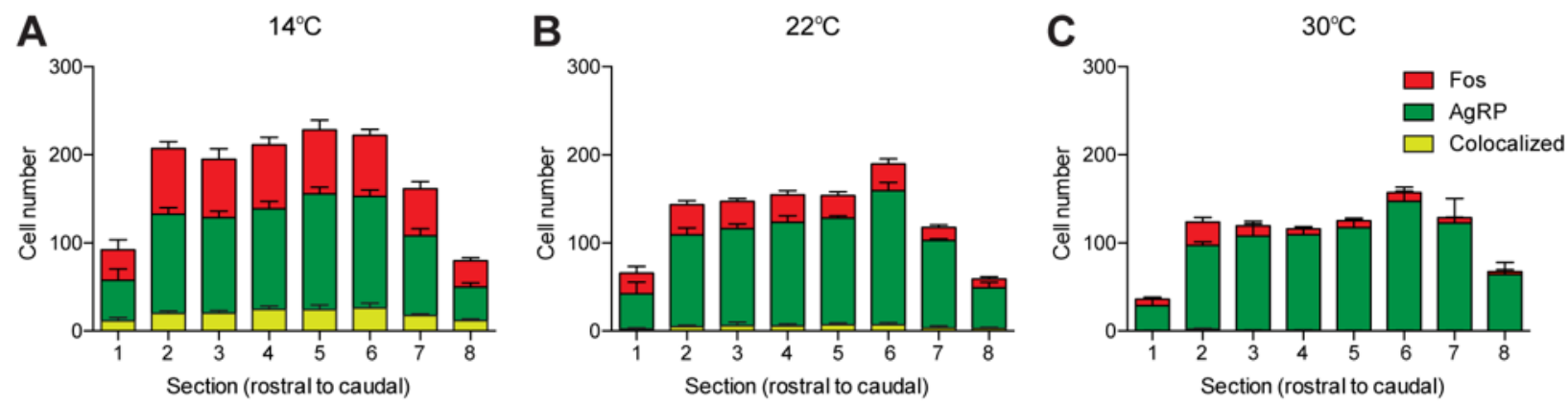

Supplemental Figure 3 (Related to Figure 3). Fos induction in AgRP neurons across entire ARC.

Fos induction in AgRP neurons across entire rostral to caudal axis of ARC after exposure to 90867 min at $(\mathbf{A}) 14^{\circ} \mathrm{C},(\mathbf{B}) 22^{\circ} \mathrm{C}$, or (C) $30^{\circ} \mathrm{C}$. 


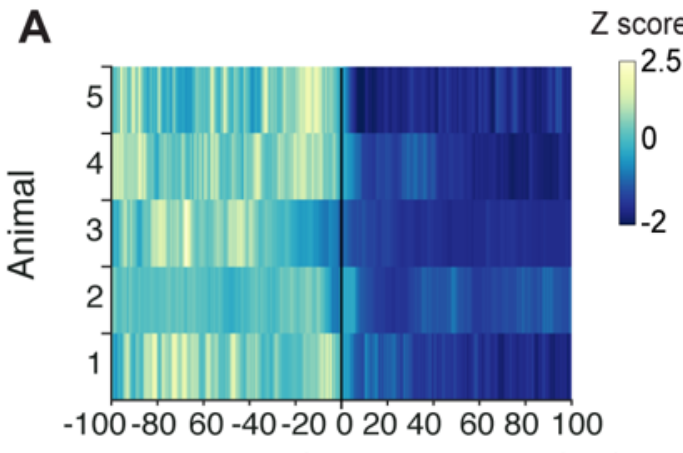

B

Time aligned to food presentation (sec)

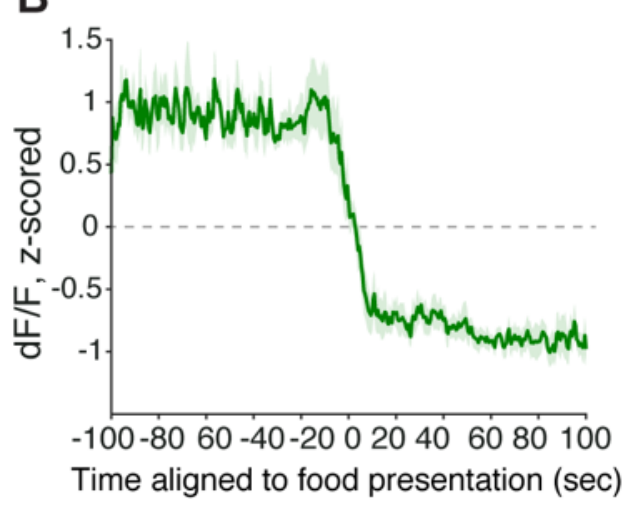

(A) Heat map of Z-scored dF/F and (B) averaged AgRP neuron GCaMP6s activity from individual overnight fasted mice presented with a food pellet, $n=5 /$ group, Mean \pm SEM. 
A
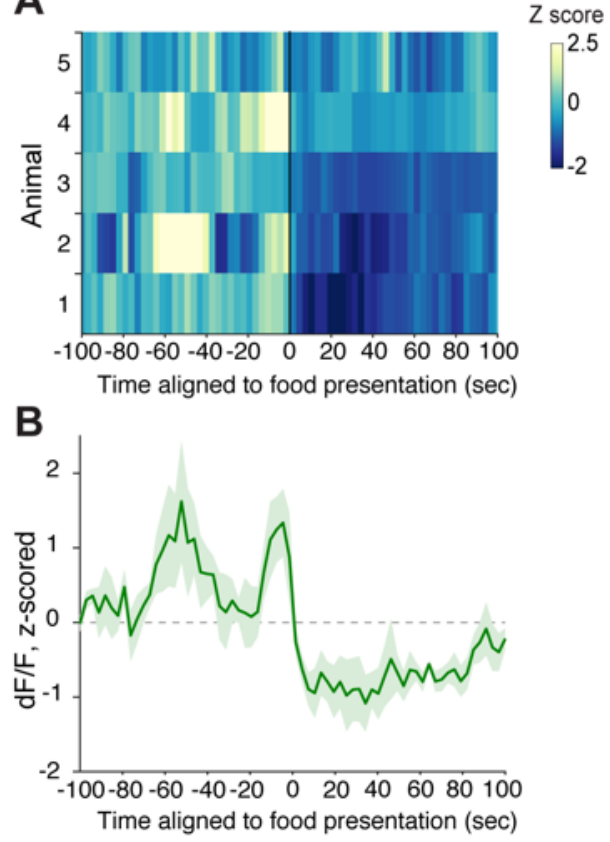

880 Supplemental Figure 5 (Related to Figure 4). AgRP neuron GCaMP6s activity is reduced by 881 food presentation in ad lib fed mice.

882

883 (A) Heat map of z-scored dF/F aligned to food pellet presentation and (B) averaged z-scored 884 GCaMP6s signal. $n=5 / g r o u p$, Mean \pm SEM. 


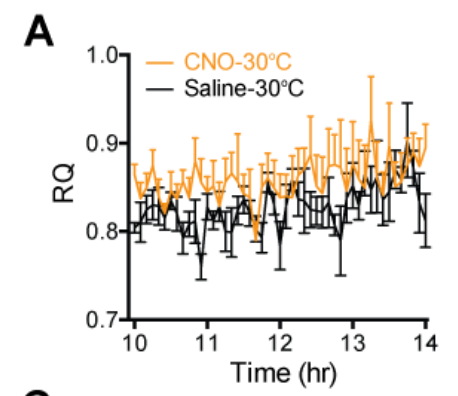

C

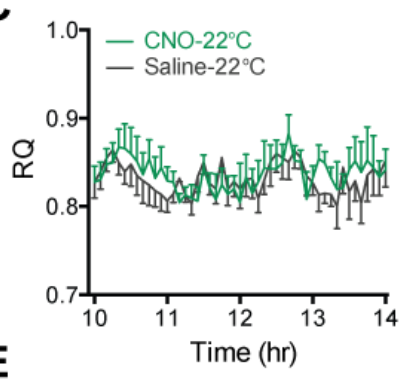

E

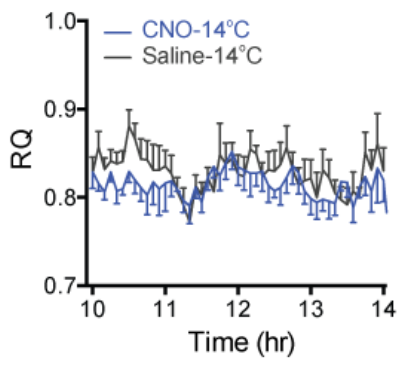

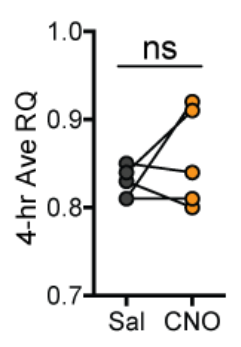

B
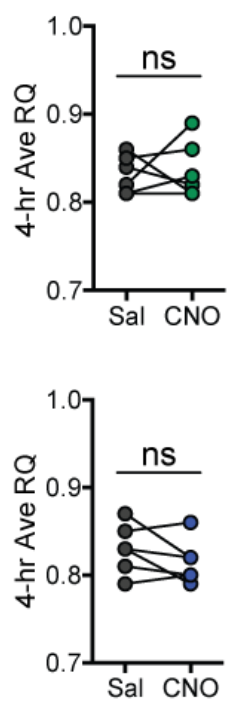
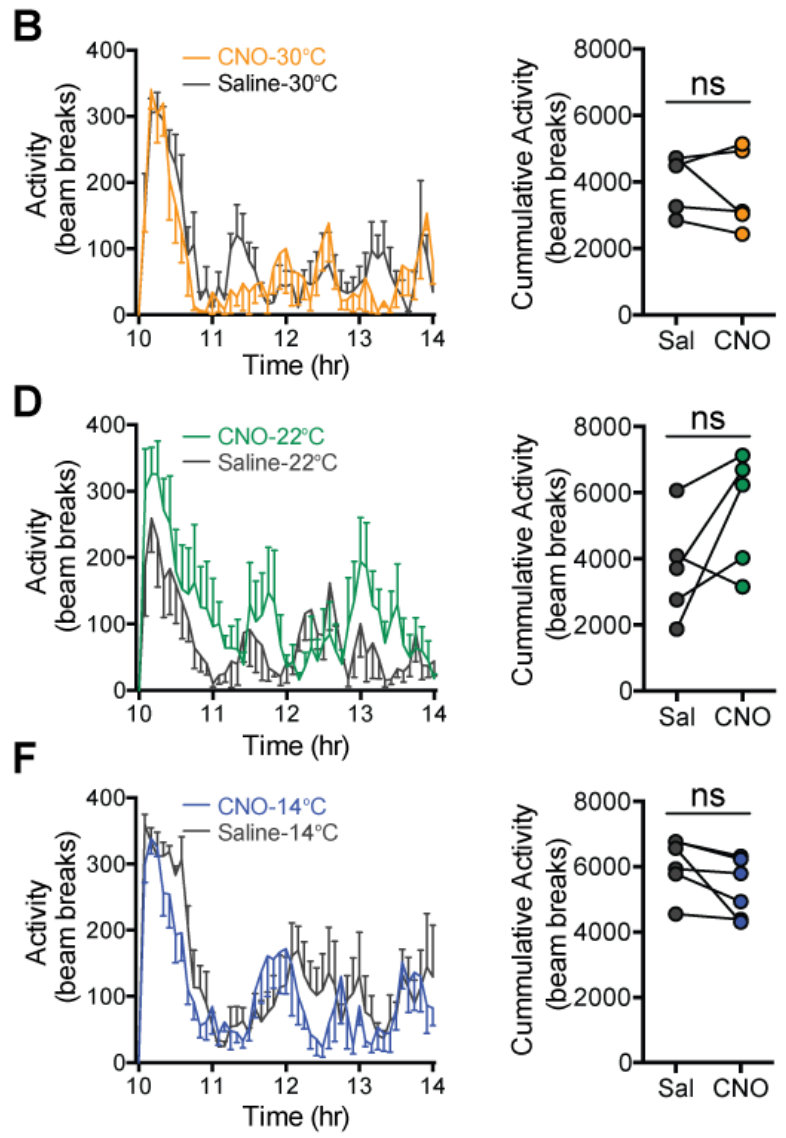

\section{Supplemental Figure 6 (Related to Figure 5). Respiratory quotient and ambulatory activity after AgRP neuron inhibition at three ambient temperatures.}

(A, C, E) 4-hr time-series and mean value for respiratory quotient (RQ), and (B, D, F) 4-hr timeseries and mean value of cumulative activity in hM4Di-eYFP AgRP-IRES-Cre mice that were housed at either $30^{\circ} \mathrm{C}, 22^{\circ} \mathrm{C}$ or $14^{\circ} \mathrm{C}$ after receiving an i.p. injection of either saline or $\mathrm{CNO}$ in a randomized, crossover manner, $n=6-8 /$ group, Mean \pm SEM. 


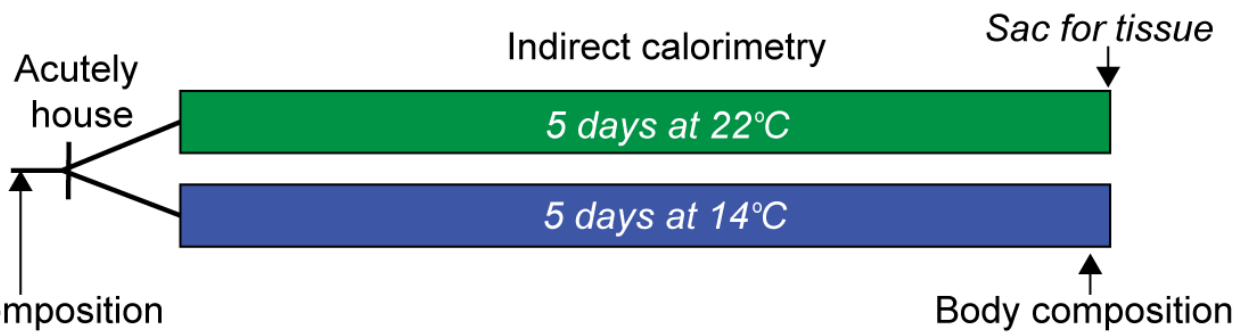

Body composition

B

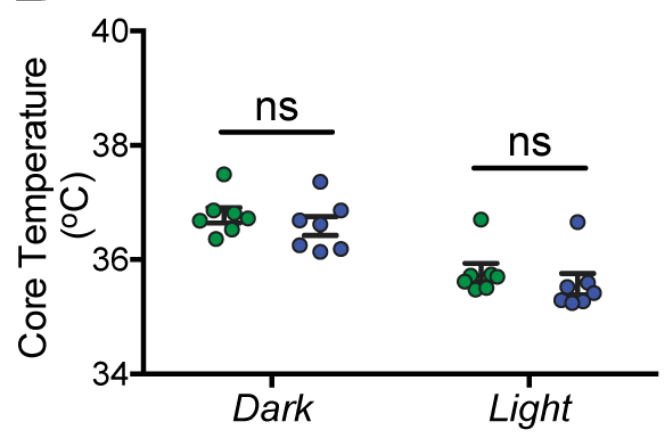

E

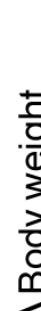

C

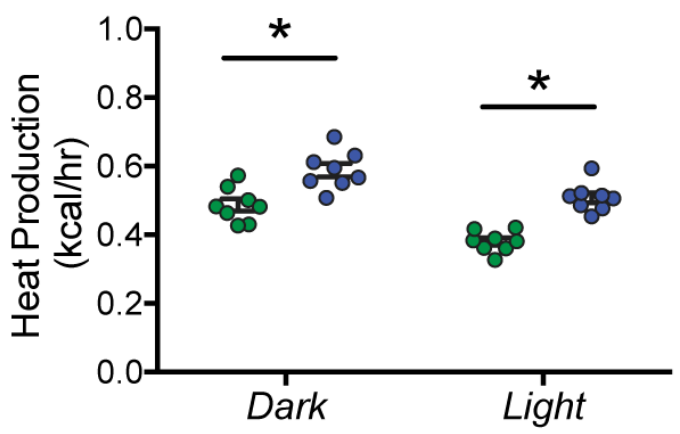

F

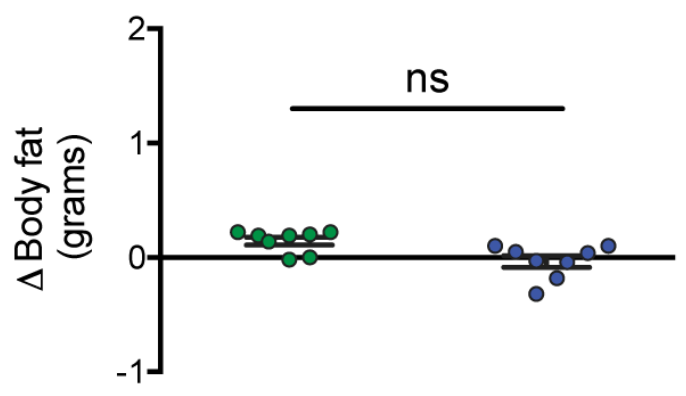

H
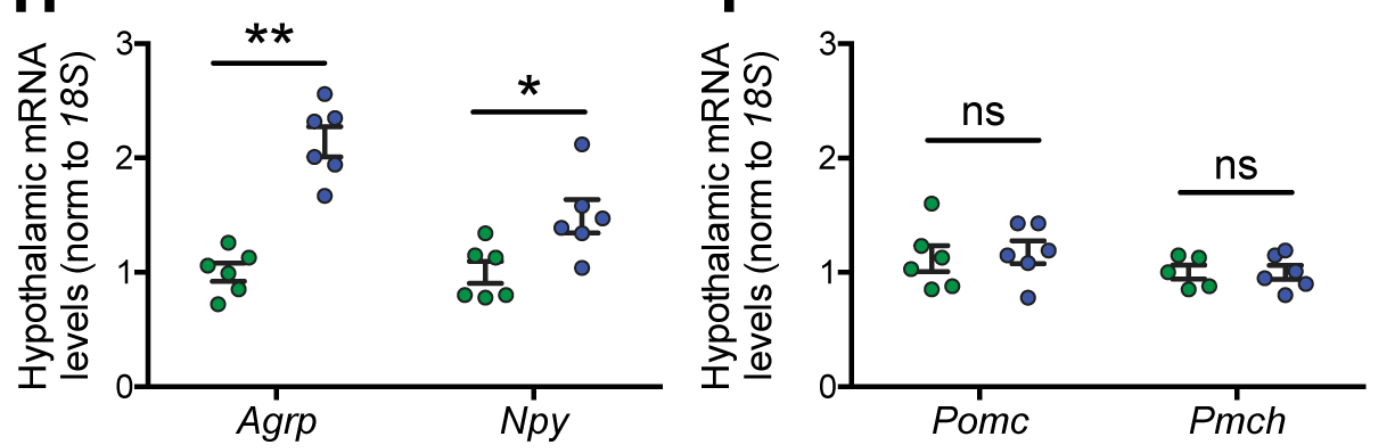

D

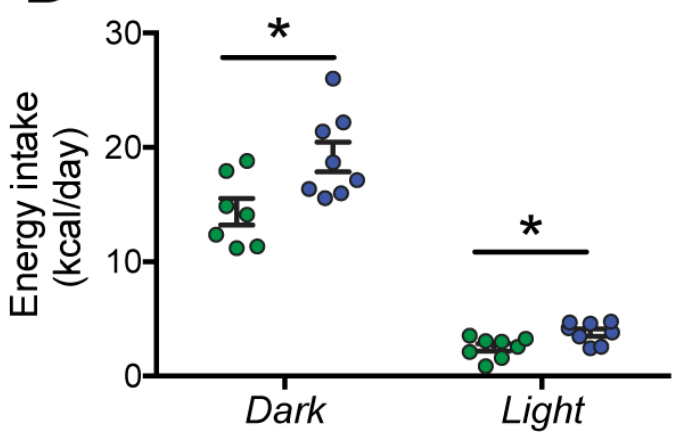

G

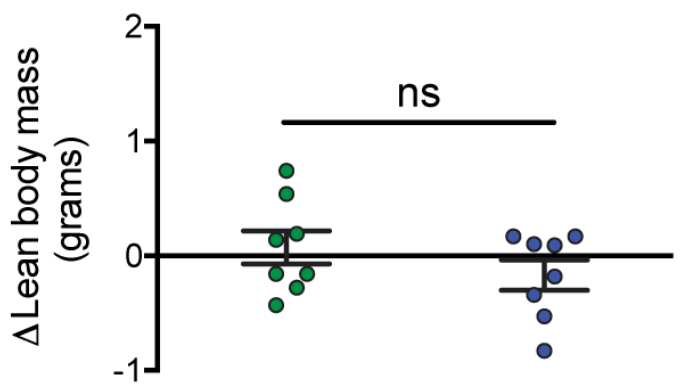

$22^{\circ} \mathrm{C}$

- $14^{\circ} \mathrm{C}$ 


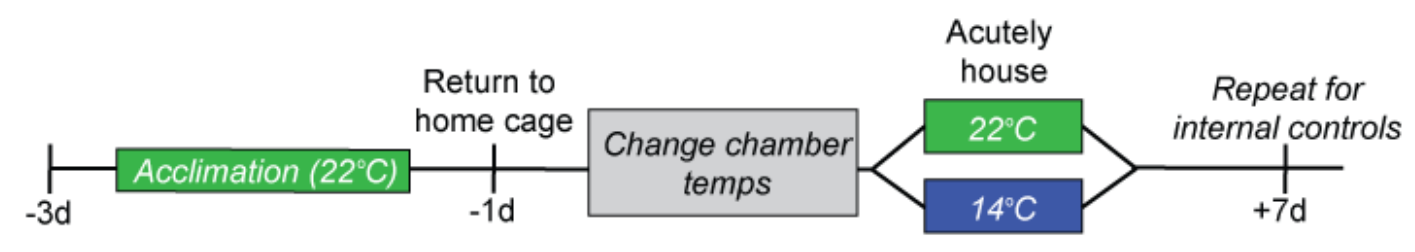

B

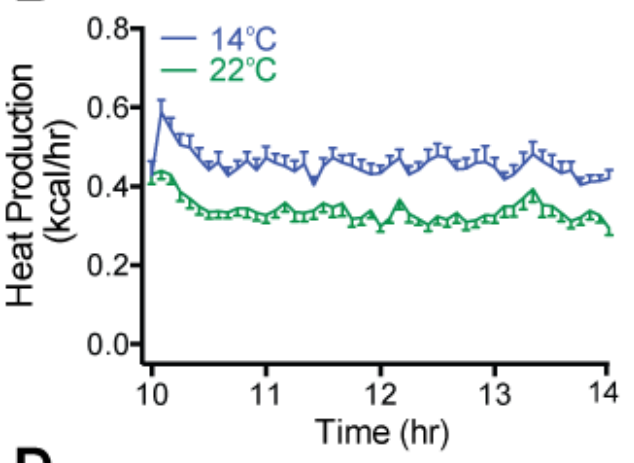

D

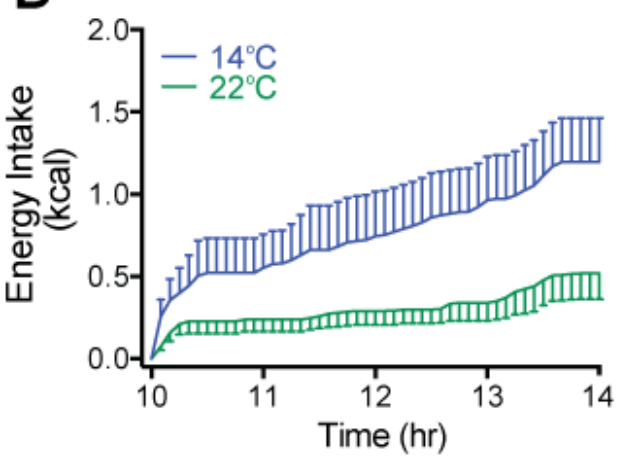

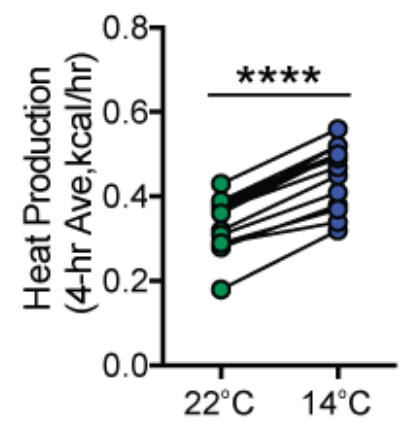

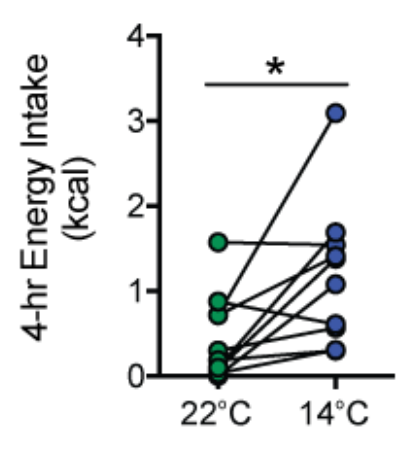

C
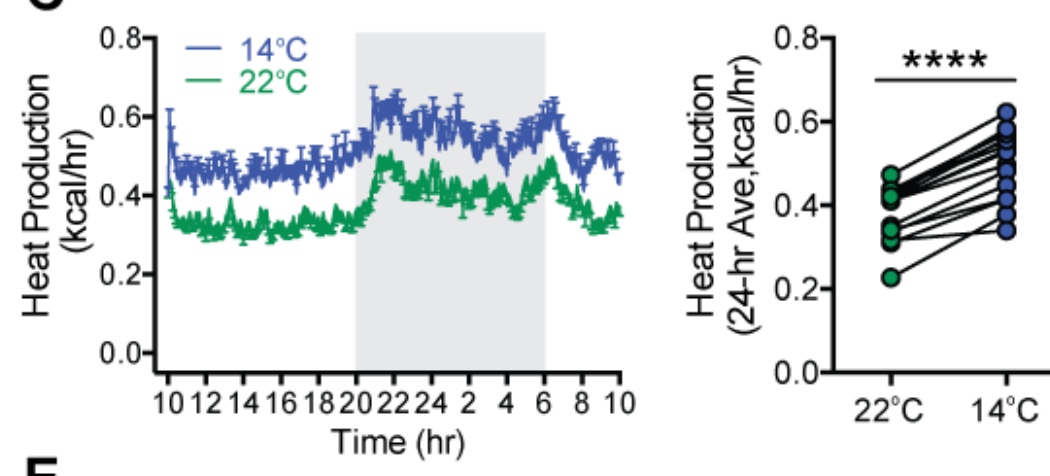

E

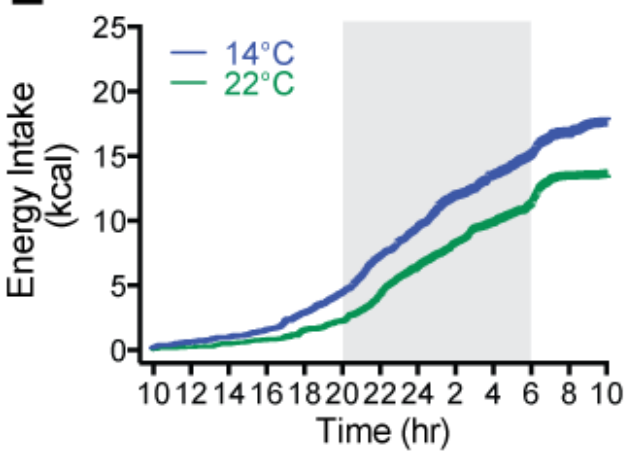

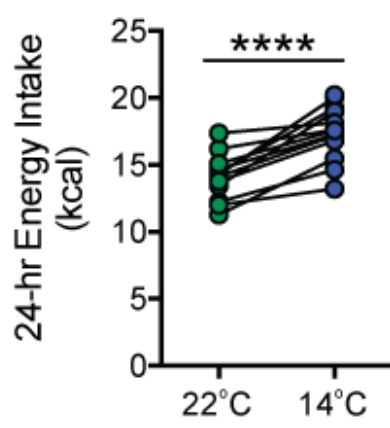


ApRxiv preprint doi: https://doi.org/10.11 020.0521 .107896 : this version posted May 25, 2020. The copyright holder for this preprint (which

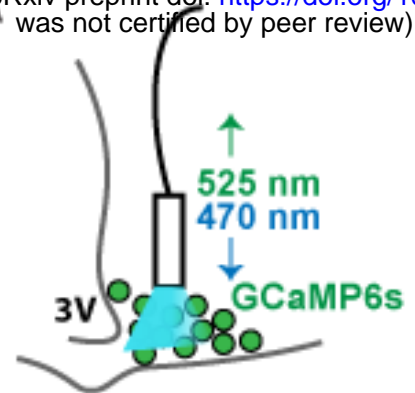

AgRP-IRES-Cre

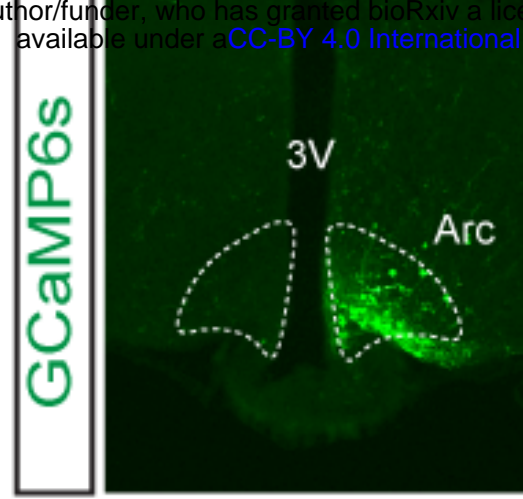
nse to display the preprint in perpetuity. It is made license.

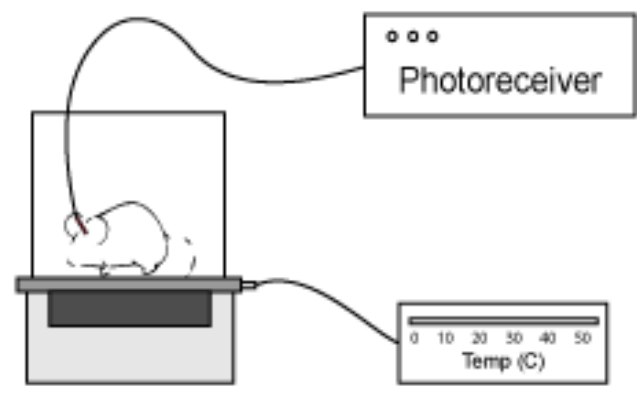

D
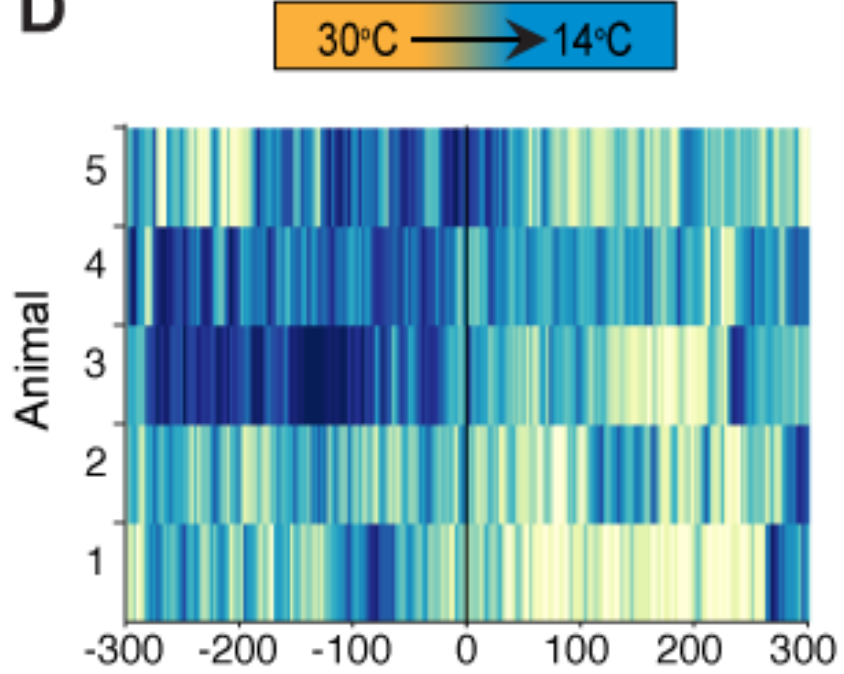

E Time (sec) aligned to temp change

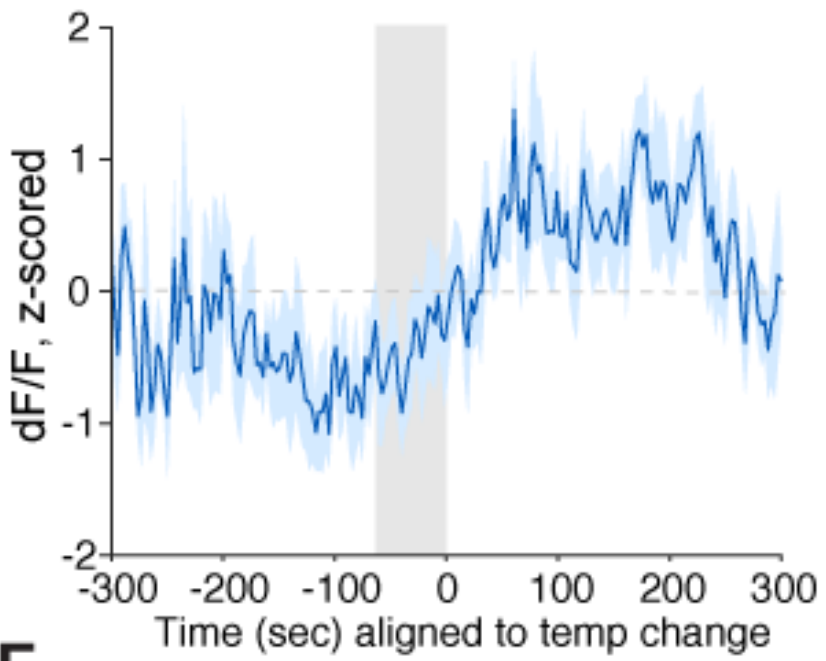

E

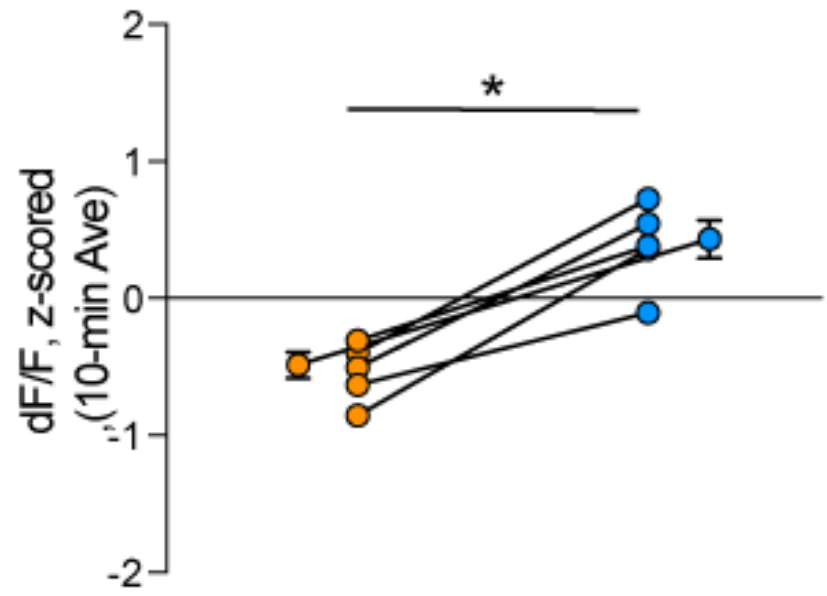

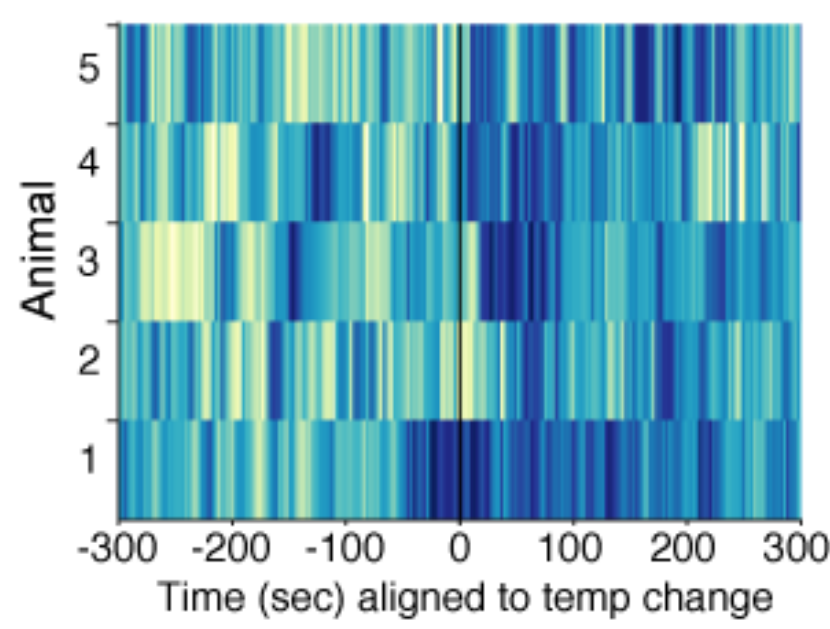

Z score

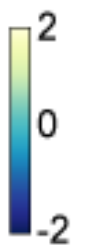

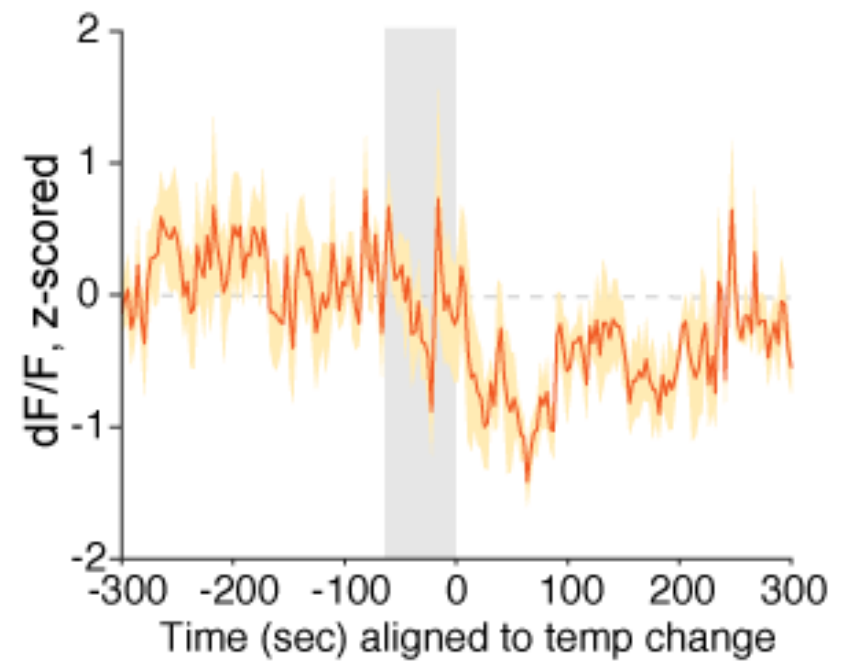

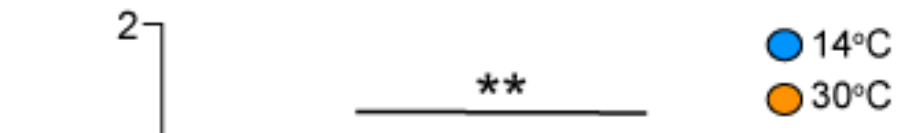




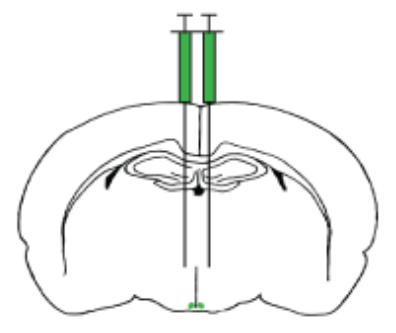

AgRP-IRES-Cre

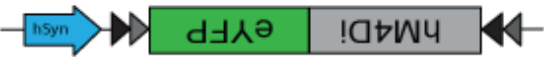

$\downarrow+$ Cre

\begin{tabular}{l|l} 
hM4Di & eYFP
\end{tabular}

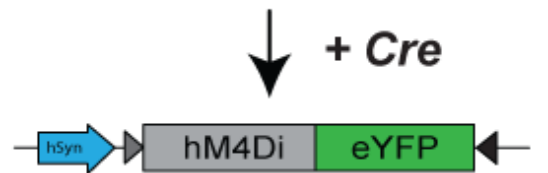

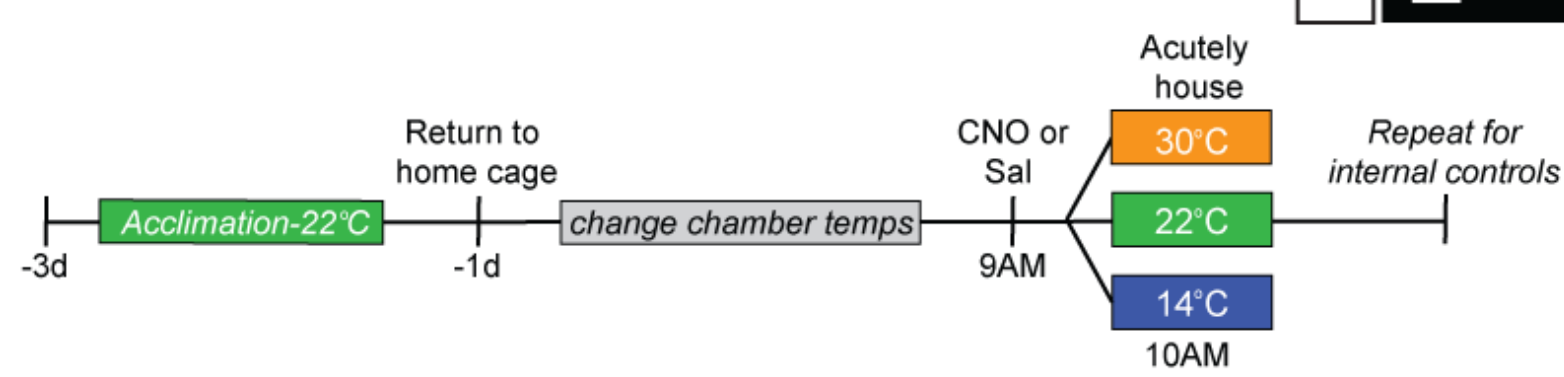

D

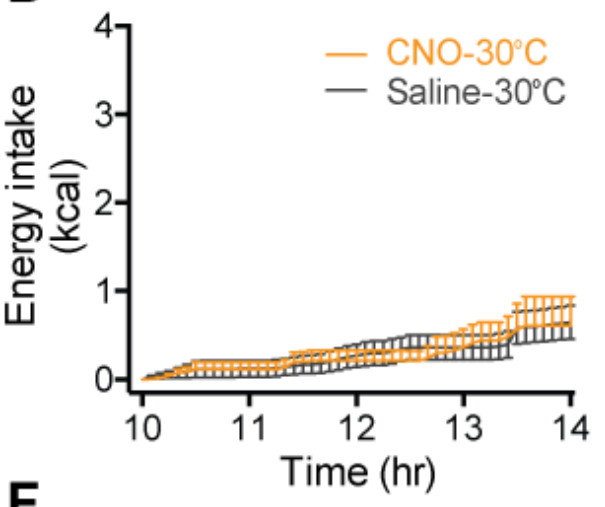

$\mathbf{F}$

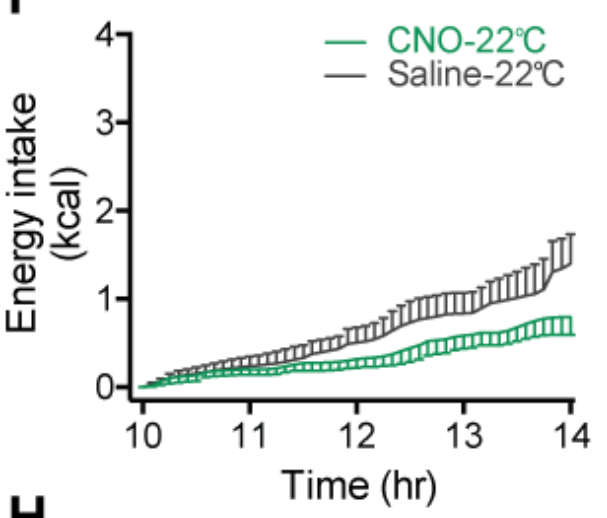

H

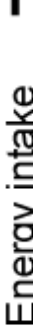
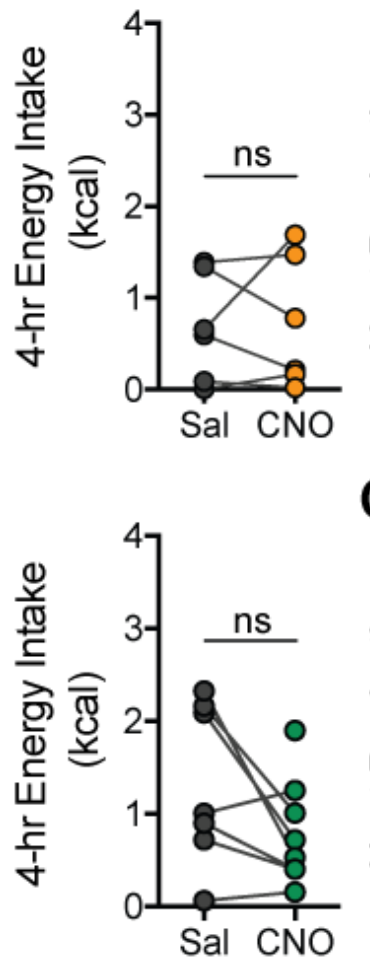

$\mathbf{G}$
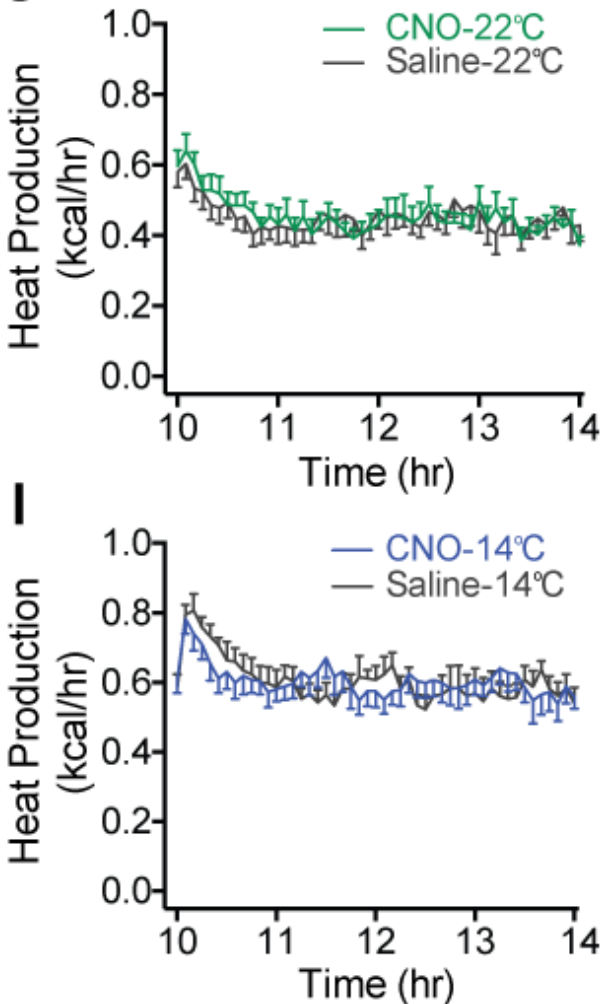
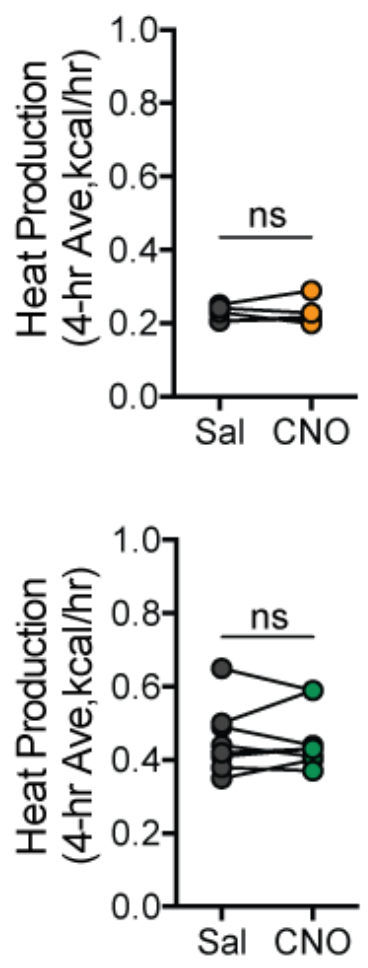

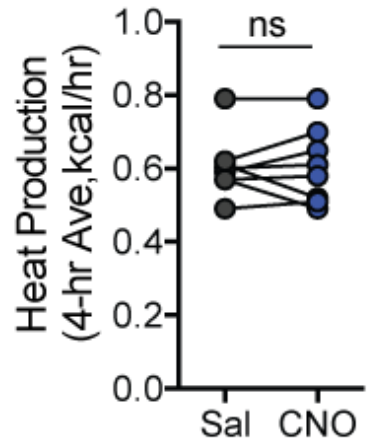



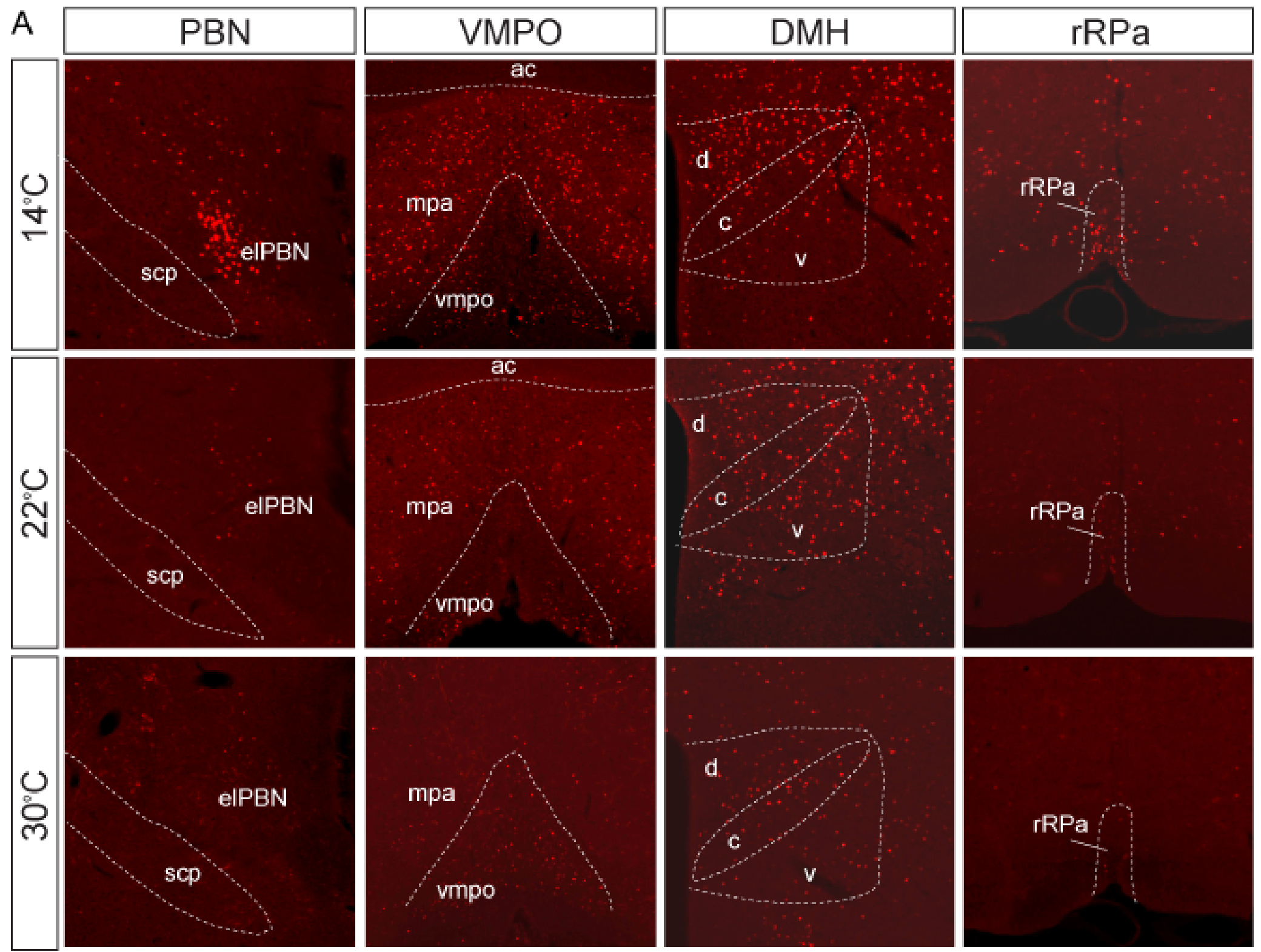

B

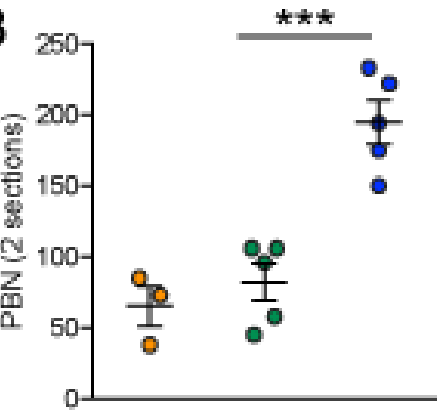

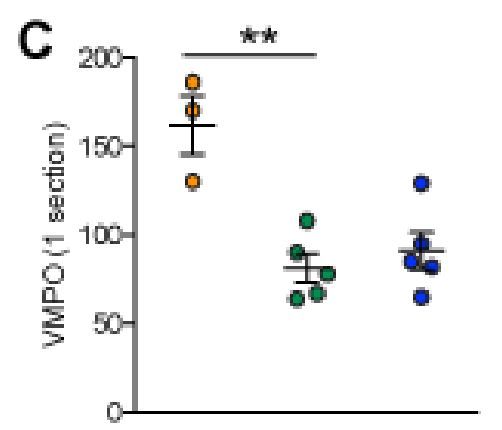

E

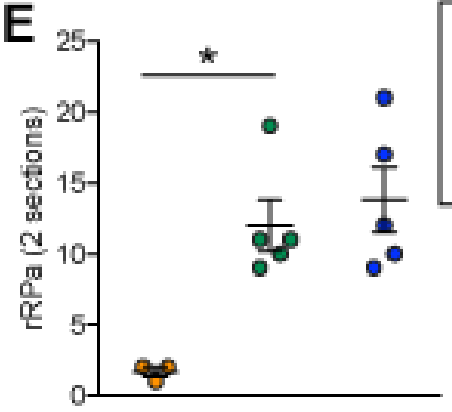

- $30^{\circ} \mathrm{C}$

- $22^{\circ} \mathrm{C}$

- $14^{\circ} \mathrm{C}$

Supplemental Figure 2 (Related to Figure 3). Fos induction in known thermoregulatory brain regions 

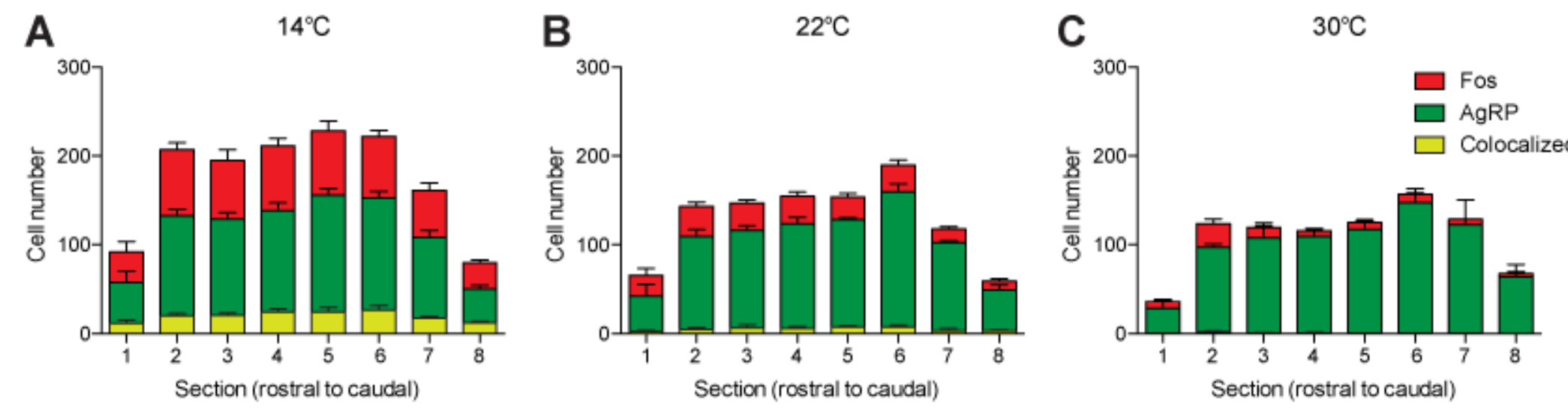

Supplemental Figure 3 (Related to Figure 3). Fos induction in AgRP neurons across entire ARC. 
A

Z score

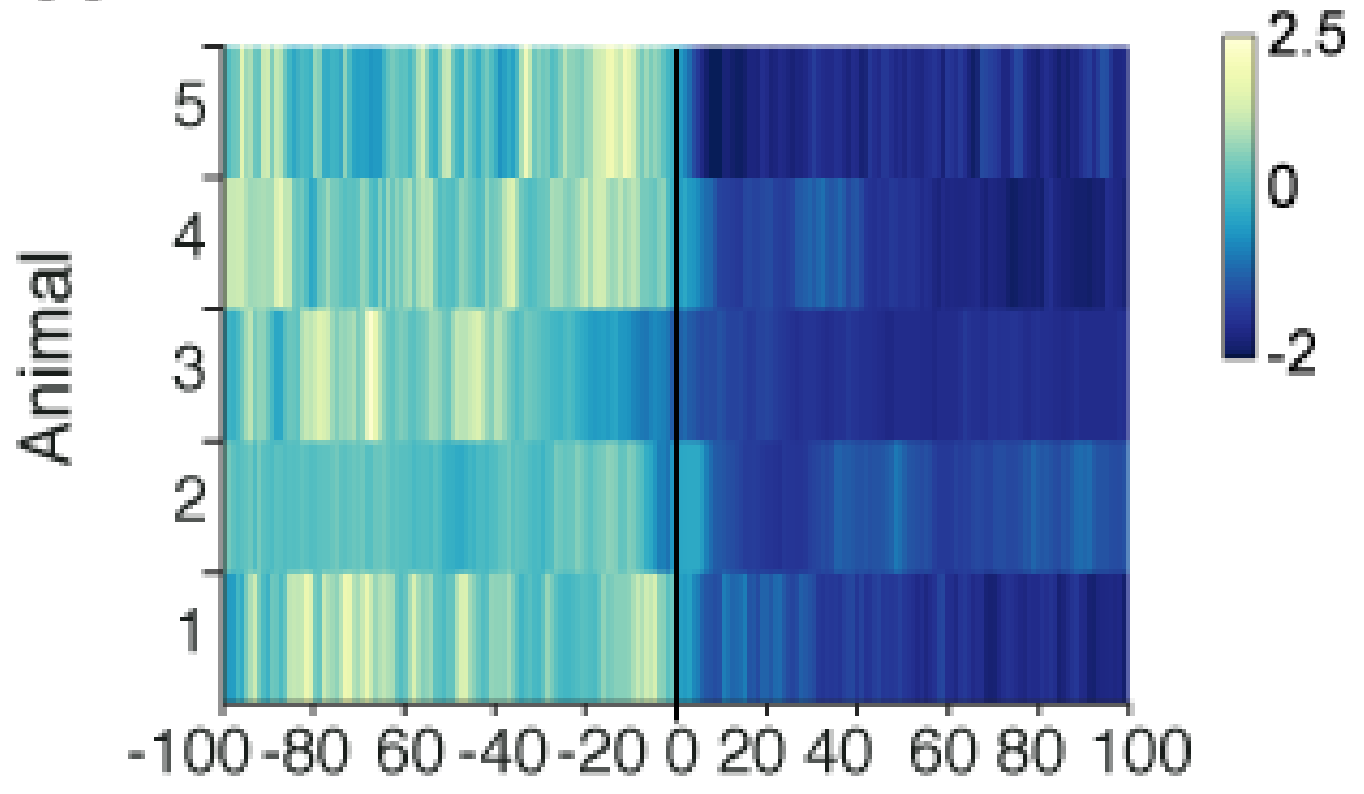

Time aligned to food presentation (sec)

B

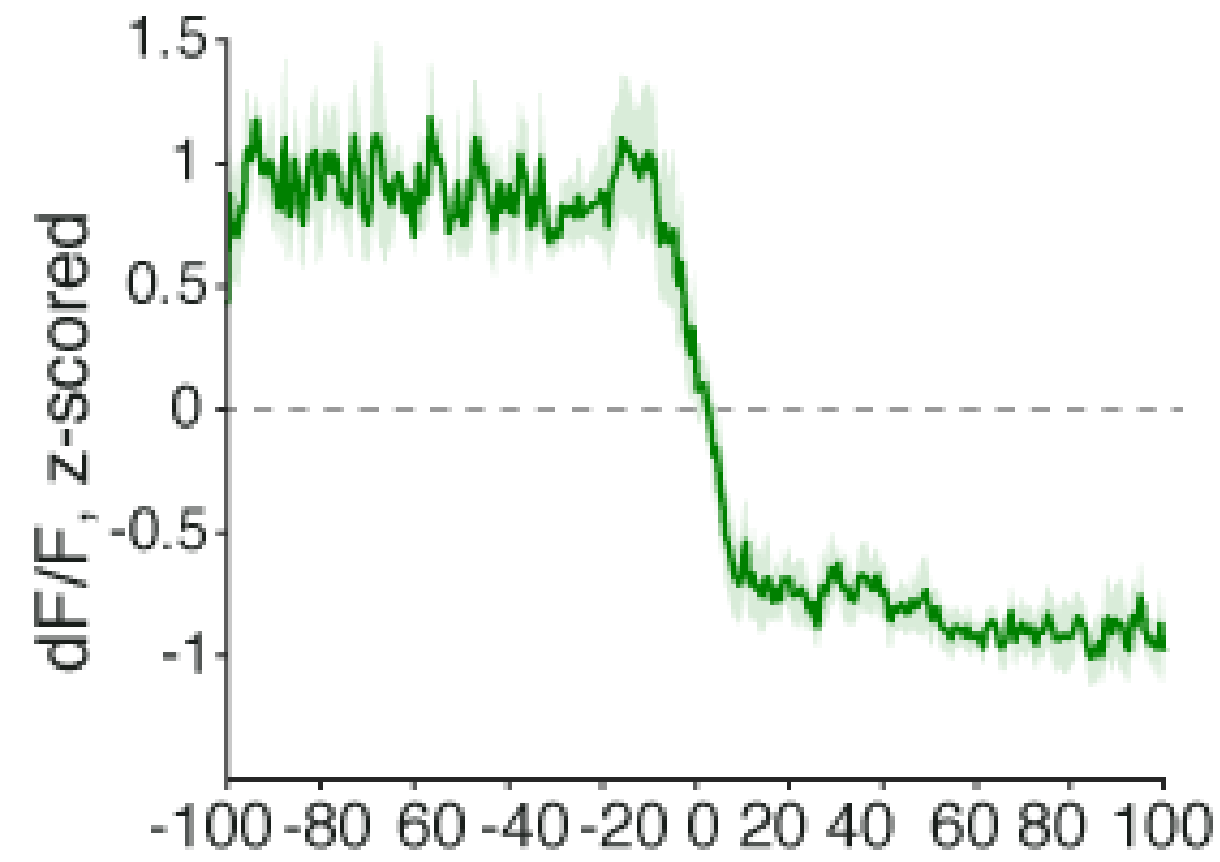

Time aligned to food presentation (sec)

\section{Supplemental Figure 4 (Related to Figure 4). Post-fast refeeding inhibits AgRP neurons}


A

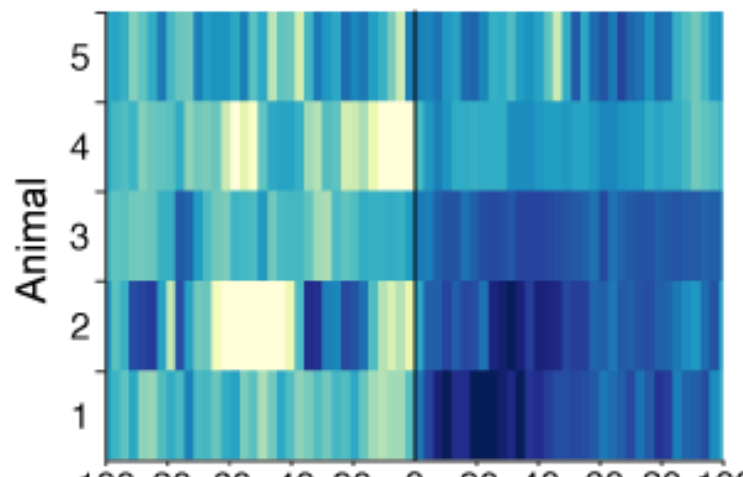

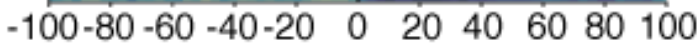

Time aligned to food presentation (sec)

B

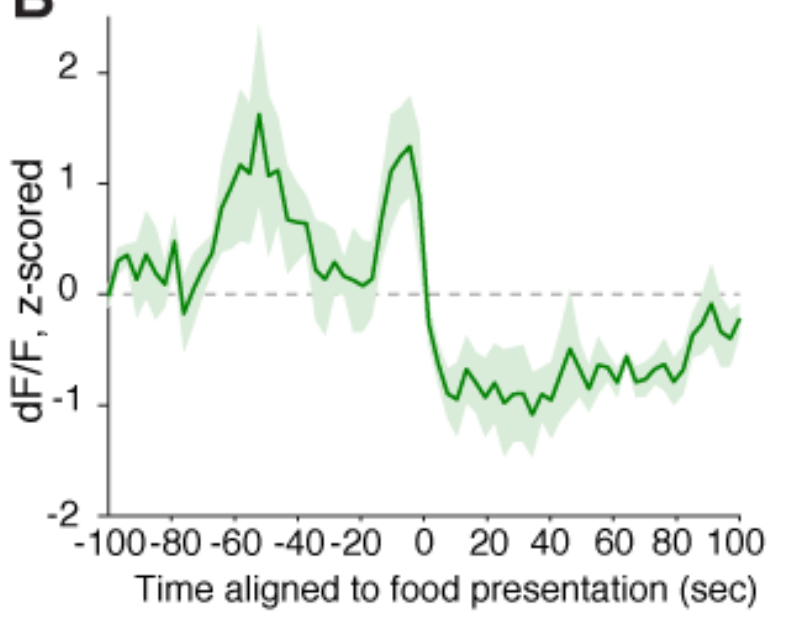

Z score

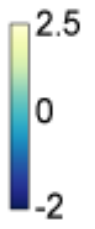

\section{Supplemental Figure 5 (Related to Figure 4).}

AgRP neuron GCaMP6s activity is reduced by food presentation in ad lib fed mice. 
A

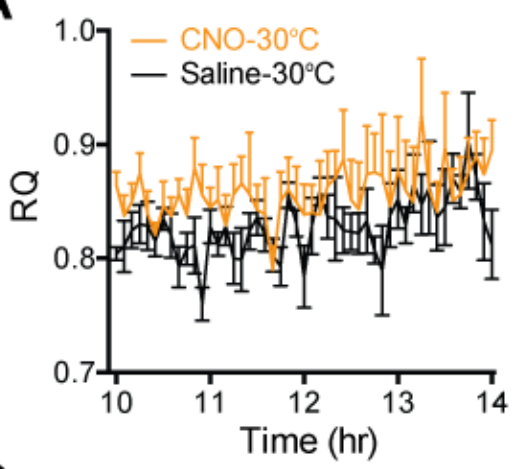

C
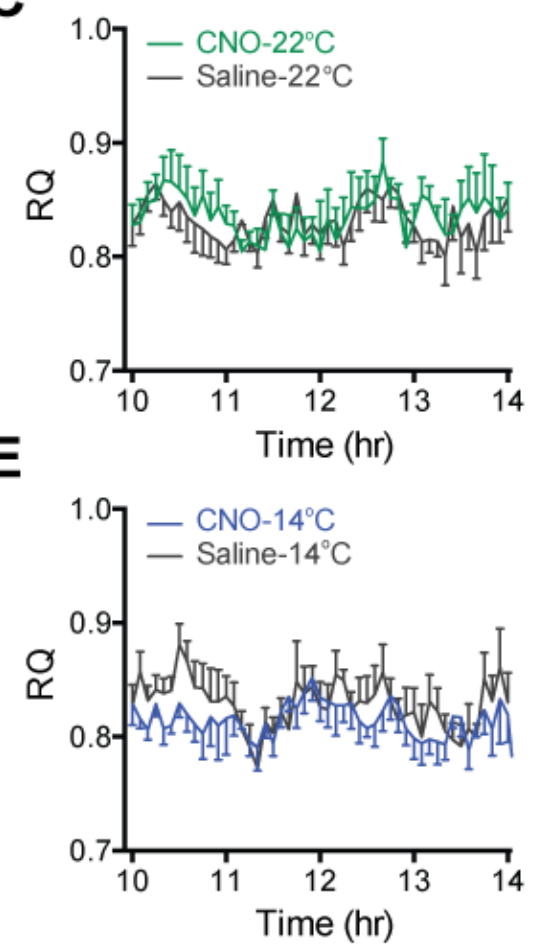

B
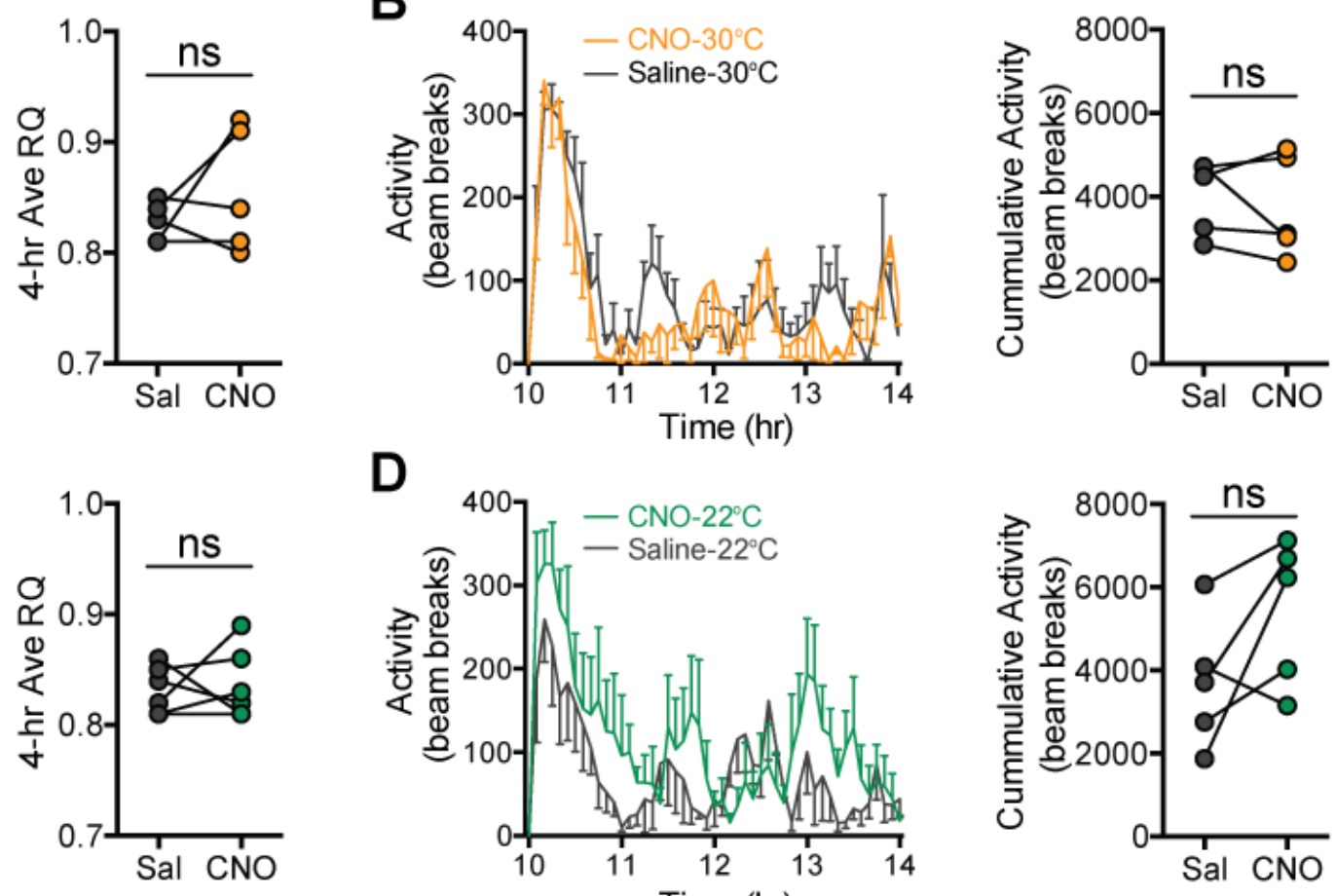

D
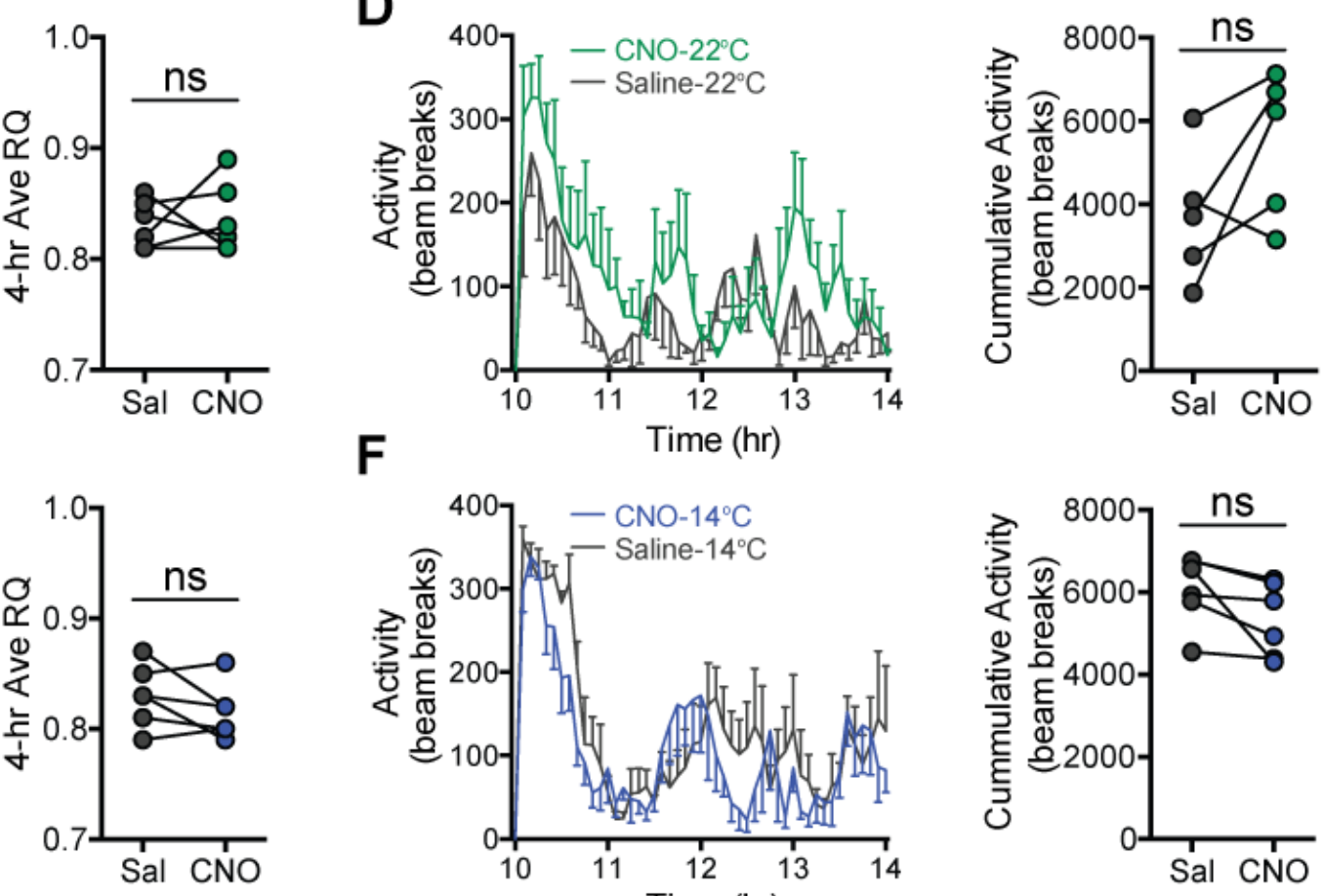
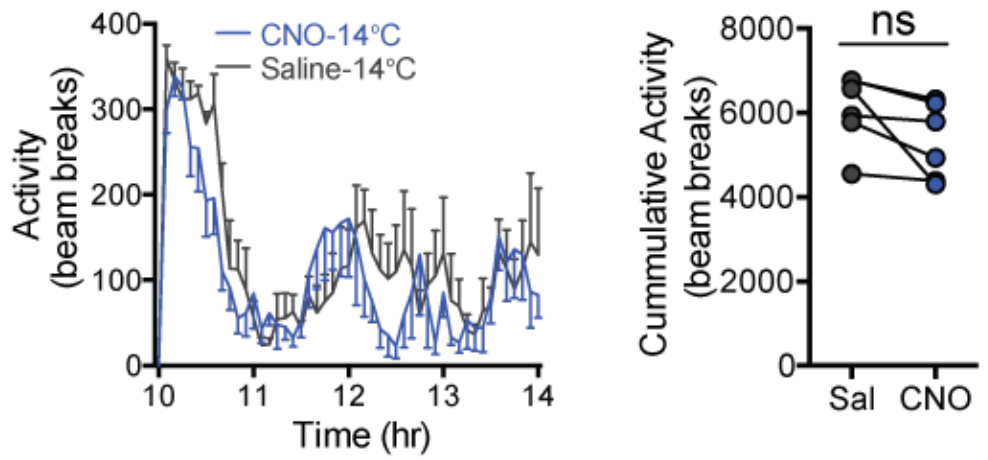